IZA DP No. 9164

The Selection of High-Skilled Migrants

Matthias Parey

Jens Ruhose

Fabian Waldinger

Nicolai Netz

June 2015 


\title{
The Selection of High-Skilled Migrants
}

\author{
Matthias Parey \\ University of Essex and IZA
}

Jens Ruhose

Ifo Institute and IZA

Fabian Waldinger

University of Warwick

\section{Nicolai Netz}

DZHW

\section{Discussion Paper No. 9164 \\ June 2015}

IZA

\author{
P.O. Box 7240 \\ 53072 Bonn \\ Germany
}

\author{
Phone: +49-228-3894-0 \\ Fax: +49-228-3894-180 \\ E-mail: iza@iza.org
}

\begin{abstract}
Any opinions expressed here are those of the author(s) and not those of IZA. Research published in this series may include views on policy, but the institute itself takes no institutional policy positions. The IZA research network is committed to the IZA Guiding Principles of Research Integrity.

The Institute for the Study of Labor (IZA) in Bonn is a local and virtual international research center and a place of communication between science, politics and business. IZA is an independent nonprofit organization supported by Deutsche Post Foundation. The center is associated with the University of Bonn and offers a stimulating research environment through its international network, workshops and conferences, data service, project support, research visits and doctoral program. IZA engages in (i) original and internationally competitive research in all fields of labor economics, (ii) development of policy concepts, and (iii) dissemination of research results and concepts to the interested public.
\end{abstract}

IZA Discussion Papers often represent preliminary work and are circulated to encourage discussion. Citation of such a paper should account for its provisional character. A revised version may be available directly from the author. 


\section{ABSTRACT}

\section{The Selection of High-Skilled Migrants*}

We measure selection of high-skilled migrants from Germany using predicted earnings. Migrants to less equal countries are positively selected relative to non-migrants, while migrants to more equal countries are negatively selected, consistent with the prediction in Borjas (1987). Positive selection to less equal countries is driven by university quality and grades, and negative selection to more equal countries by university subject and gender. Migrants to the U.S. are highly positively selected and concentrated in STEM fields. Our results highlight the relevance of the Borjas model for high-skilled individuals when credit constraints and other migration barriers are unlikely to be binding.

JEL Classification: $\quad F 22, \mathrm{~J} 24, \mathrm{~J} 31, \mathrm{~J} 61$

Keywords: international migration, high-skilled migrants, selection, inequality, Roy/Borjas model

Corresponding author:

Matthias Parey

University of Essex

Department of Economics

Wivenhoe Park

Colchester, CO4 3SQ

United Kingdom

E-mail: mparey@essex.ac.uk

\footnotetext{
* We thank Clement de Chaisemartin, Thomas Crossley, Christian Dustmann, Tim Hatton, and Gordon Kemp for helpful comments and suggestions. We also thank seminar participants in Berlin, Essex, and Warwick, as well as attendees of the "Bergen, UCL, Warwick - Topics in Labour Economics Workshop", the $12^{\text {th }}$ IZA Annual Migration Meeting $\left(\mathrm{AM}^{2}\right)$ and the $5^{\text {th }}$ Migration Topic Week for their valuable feedback. We thank Kolja Briedis, Christian Kerst, and Gregor Fabian for providing access to the DZHW Graduate Panels and for their hospitality. Parey gratefully acknowledges the support of the ESRC Research Centre on Micro-Social Change (MiSoC) at the University of Essex. This study uses data from the Swiss Labour Force Survey (Schweizerische Arbeitskräfteerhebung, BFS).
} 


\section{Introduction}

International migration of high-skilled individuals has risen dramatically in recent decades (Docquier and Rapoport, 2012). Between 2000 and 2006, the United States attracted 1.9 million tertiary-educated migrants, and European OECD countries attracted 2.2 million of these migrants (Widmaier and Dumont, 2011). In the year 2000, high-skilled migrants represented about 11 percent of the tertiary-educated population in OECD countries (Brücker et al., 2012). In the United States, about 19 percent of the working-age population with a bachelor's degree or higher were foreign-born in 2013. In certain fields such as science, technology, engineering, and mathematics (STEM) even more than 30 percent were foreign-born. ${ }^{1}$

Access to talent is central to firms' success and has become more important in economies where ideas drive technological progress (Chambers et al., 1998). When the home-grown talent pool is insufficient, the ability to attract high-skilled migrants is crucial for improving the quality of a country's workforce and its innovative capacity. Immigrants with STEM degrees are regarded as particularly important. In fact, immigrants outperform U.S. natives in patenting, commercializing patents, and publishing in scientific journals (Hunt, 2011). A deeper understanding of the selection of high-skilled migrants is therefore important - for sending and receiving countries alike. ${ }^{2}$

While migrant selection has been studied extensively since Borjas (1987) outlined theoretical predictions for selection, few papers have studied the selection of highskilled migrants. A notable exception is Grogger and Hanson's (2015) study of foreign-born $\mathrm{PhD}$ graduates, who are positively selected regarding the intention to stay in the United States after completing their PhDs. This study, however, does not consider how relative earnings inequality - which lies at the heart of the Borjas selection model - affects staying intentions. ${ }^{3}$

We use rich survey data on German university graduates to investigate how the

\footnotetext{
${ }^{1}$ Own calculations based on the 2013 American Community Survey (Ruggles et al., 2010).

${ }^{2}$ Recent papers have highlighted the role of taxes for the migration of inventors and soccer players (Akcigit et al., 2015, Kleven and Landais, 2013).

${ }^{3}$ See section 1.2 for a review of empirical papers investigating migrant selection across the entire skill distribution. A number of papers have investigated the effect of high-skilled migrants on the receiving economy and on innovation in particular. In the United States, high-skilled migrants increase patenting at the state level (Hunt and Gauthier-Loiselle, 2010). At the city level, highskilled migrants from China and India increase overall patenting but do not increase patenting of natives (Kerr and Lincoln, 2010). Mathematicians who migrated to the United States after the collapse of the Soviet Union lowered publication output of U.S. mathematicians (Borjas and Doran, 2012). German Jewish chemists who were dismissed from Nazi Germany and migrated to the United States increased patenting in research fields of émigrés (Moser et al., 2014). Another recent strand of the literature has shown that high-skilled migrants also affect native employment in U.S. firms (Kerr et al., 2015, Doran et al., 2014).
} 
selection of high-skilled migrants depends on relative earnings inequality in home and receiving countries. Because German university attendance rates are relatively low in international comparison, we study selection within the top 11 percent of the educational distribution. ${ }^{4}$ The university graduates in our data are followed into the labor market until five years after graduation, even if they move abroad. We therefore observe whether they decide to stay and work in Germany, migrate to a less equal country, or migrate to a more equal country after completing their studies.

A basic version of the Borjas (1987, 1991) model, building on Roy (1951), predicts that migrants to less equal countries, such as the United States, should be positively selected, while migrants to more equal countries, such as Denmark, should be negatively selected. We test these predictions for a sample of high-skilled individuals and measure selection using predicted earnings. We first estimate an augmented Mincer regression for graduates who work in Germany. We then use the estimated returns and each graduate's personal characteristics to construct predicted earnings, independently of whether the graduate stays in Germany or migrates abroad. Our data contain a rich set of personal characteristics including family background, high-school education (including school grades), university education (including the specific university, subject, and final grades), and information on mobility before enrolling at university. These detailed characteristics allow us to obtain predicted earnings as a precise measure of individual earnings potential, so that we can differentiate between high- and low-productivity university graduates.

For our main results, we compare cumulative density functions of predicted earnings for three groups of graduates: graduates who stay in Germany, graduates who migrate to less equal countries, and graduates who migrate to more equal countries. To classify destinations into either more or less equal countries, we construct new inequality measures for university graduates that are based on individual-level income surveys from 20 countries. German inequality for high-skilled individuals lies in the middle of the relevant set of countries (Figure 1). This allows us to investigate selection to less equal countries (such as the United States) and to more equal countries (such as Denmark).

We find that the selection of university graduates is consistent with the predictions of the basic Roy/Borjas model. Individuals who migrate to less equal countries have significantly higher predicted earnings than non-migrants. Individuals who migrate to more equal countries, in contrast, have significantly lower predicted earnings

\footnotetext{
${ }^{4}$ The German Statistical Office reports that 575,000 out of a population of 4,744,000 people between age 35 and 39, and 633,000 out of 6,260,000 people between age 40 and 44 , had a university degree in 2012 (DESTATIS, 2013, p. 27). This corresponds to a university graduation rate of 10.97 percent for the cohorts studied in this paper.
} 
Figure 1: Earnings inequality among the high-skilled: Ratio of 75 th to 25th percentile in the earnings distribution of university graduates

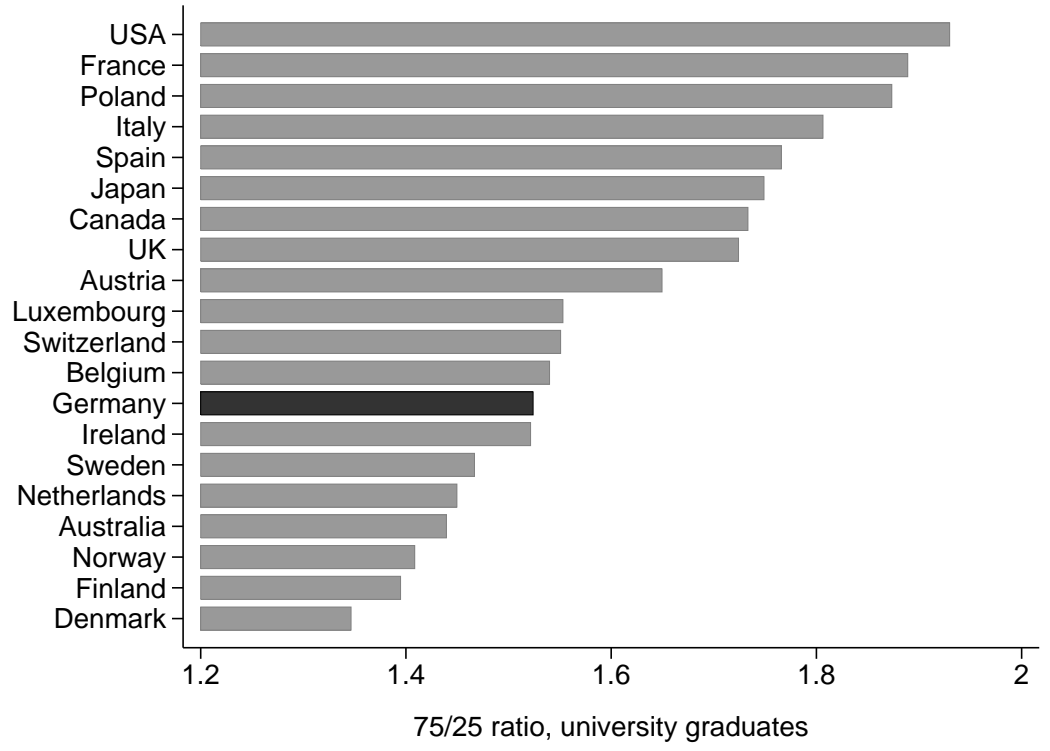

Notes: The figure shows the ratio of the 75 th to the 25 th percentile in the earnings distribution of university graduates. Own calculation based on country-specific data sources (see Table A.1), showing averages over the period 1998 to 2010. Details on data sources and the construction of inequality measures are reported in section 2.2 and Data Appendix B.1.

than non-migrants. These findings hold along the whole distribution of predicted earnings.

The coefficients of the Mincer regression, which are the basis of our earnings prediction, might be biased if migrants were non-randomly selected from the population of graduates in a way not captured by our observed covariates. We therefore address potential selection in the augmented Mincer regression using a sample selection correction (Heckman, 1979). In the selection equation, we use the availability of study abroad programs as an instrumental variable to predict whether individuals work in Germany instead of working abroad. Changes in the number of ERASMUS places are a good predictor for international migration (Parey and Waldinger, 2011). Thus, they allow us to correct for selection in the augmented Mincer regression. When we implement the sample selection correction, the coefficients in the corrected Mincer regression are very similar to the uncorrected ones. We can therefore confirm our main results even after the Heckman correction.

Our main results compare skills for three groups: non-migrants, migrants to unequal countries, and migrants to equal countries. Furthermore, we split unequal and equal countries into two groups each. As predicted by the model, migrants to very unequal countries are most positively selected; migrants to somewhat unequal coun- 
tries are somewhat positively selected; migrants to somewhat equal countries are somewhat negatively selected; and migrants to very equal countries are most negatively selected. We also analyze selection across the 19 major destination countries. On average, migrants to destinations with higher inequality have higher predicted earnings than migrants to destinations with lower inequality, again confirming the predictions of the Roy/Borjas model.

Arguably, migration decisions might also be driven by other factors that may be correlated with cross-country inequality. We show that our results are robust to controlling for potentially confounding factors in a cross-country regression of mean selection patterns and in individual-level quantile regressions that estimate selection across the earnings distribution. Specifically, the results are robust to controlling for differences in mean earnings, unemployment rates of university graduates, expenditures on family benefits, and life satisfaction. We also show that the results are robust to using alternative inequality measures.

Additionally, we investigate the selection of migrants to European countries only. Migration costs to these countries are particularly low because workers can move freely between European countries without applying for work visas. In this sample, migrants to less equal countries are again positively selected, while migrants to more equal countries are negatively selected. We also investigate the selection of migrants to Austria and Switzerland. Austria and Switzerland are very similar to Germany along many different dimensions, such as labor market institutions, benefit systems, language, and culture. Furthermore, migration costs to these countries are low because both countries share a border with Germany, and because Germans who migrate to these countries do not need work visas. Importantly, however, earnings inequality among university graduates is higher in both Austria and Switzerland than in Germany. Consistent with the predictions of the basic Roy/Borjas model, we find that high-skilled migrants from Germany to both Austria and Switzerland are positively selected.

In additional results, we decompose predicted earnings to identify the characteristics that explain the observed selection patterns. Positive selection to less equal countries is mostly driven by graduates' university career and parental background. Graduates who migrate to less equal countries have better university grades, attend better universities, and come from families with a higher socio-economic background. Negative selection to more equal countries is mostly driven by university subject, gender, and university quality. Graduates who migrate to more equal countries have studied subjects with lower returns in the labor market, they are more likely to be female, and they attend universities where graduates have lower earnings potential. 
Interestingly, migrants to more equal destinations are, in fact, positively selected in terms of university grade and family background. This decomposition shows that selection may not be uniform across all characteristics. The high-skilled migrants in our study, for example, are positively selected in terms of university grades, regardless of relative earnings inequality in their home and destination countries. Predicted earnings, as a summary measure of many charactistics, however, show that migrants to more equal countries are negatively selected, while migrants to more equal countries are positively selected. ${ }^{5}$ Predicted earnings therefore provide a comprehensive summary measure of expected productivity that drives migration decisions.

In the final section of the paper, we investigate selection to the United States, which is one of the most important destinations of high-skilled migrants from Germany. In the United States, earnings inequality among university graduates is much higher than in Germany. As predicted by the Roy/Borjas model, high-skilled individuals who migrate from Germany to the United States are positively selected, compared to non-migrants in Germany. Migrants to the United States are positively selected across almost all characteristics, but the most important factors are university subjects, university grades, university quality, and gender. Migrants from Germany to the United States are particularly concentrated in high-paying STEM fields.

Using data from the American Community Survey, we also investigate how highskilled migrants from Germany compare to high-skilled natives in the United States. We find that high-skilled individuals who migrate from Germany to the United States are also positively selected compared to U.S. natives, in particular because they are concentrated in higher-paying STEM fields, and because they have more advanced degrees than native U.S. college graduates. These results indicate that high-skilled individuals who migrate from Germany to the United States are not only positively selected compared to Germans who do not migrate, but also compared to non-migrants in the United States.

\footnotetext{
${ }^{5} \mathrm{~A}$ multi-dimensional extension of the Roy/Borjas model indicates that focusing on a single characteristic may not reflect the overall pattern of selection, depending on the correlation with other relevant characteristics. See Dustmann et al. (2011) for a model with two types of skills.
} 


\section{A Model of Migrant Selection and Existing Em- pirical Evidence}

\subsection{Roy/Borjas Model of Migrant Selection}

In his seminal work, Borjas $(1987,1991)$ proposes a theoretical framework for understanding the selection of international migrants. To motivate our empirical analysis, we use important insights of the Roy/Borjas model to highlight the predictions for selection. Individuals decide whether to migrate based on earnings opportunities abroad $\left(w_{1}\right)$ and at home $\left(w_{0}\right)$, and migration costs $(c)$. In this framework, potential log earnings consist of an observed component $\left(\theta_{j}\right.$, where $j=0$ indicates home and $j=1$ indicates abroad) and an unobserved component $\left(\epsilon_{j}\right)$ :

$$
\begin{aligned}
& \log w_{0}=\theta_{0}+\epsilon_{0} \\
& \log w_{1}=\theta_{1}+\epsilon_{1} .
\end{aligned}
$$

Taking migration costs $(c)$ into account, individuals will move abroad if the wage gain is larger than the migration costs:

$$
\text { Migrate }=1 \text { if } \theta_{1}+\epsilon_{1}>\theta_{0}+\epsilon_{0}+c .
$$

The vector of potential outcomes is $\left(\theta_{0}, \theta_{1}, \epsilon_{0}, \epsilon_{1}\right)$. For tractability, we assume that the outcome vector is jointly normally distributed with means $\left(\mu_{0}, \mu_{1}, 0,0\right)$ and variances $\left(\sigma_{\theta_{0}}^{2}, \sigma_{\theta_{1}}^{2}, \sigma_{\epsilon_{0}}^{2}, \sigma_{\epsilon_{1}}^{2}\right)$. Mean earnings at home and abroad are represented by $\mu_{j}$, and $\sigma_{\theta_{j}}^{2}$ represents the variance of the observed component in each country. We allow each type of skills (observables and unobservables) to be correlated across countries, but not across types. $\sigma_{\theta_{0}, \theta_{1}}$ is the covariance in the observed component across countries. We refer to the corresponding correlation as $\rho_{\theta}$. While our framework incorporates observed and unobserved earnings, this does not affect the underlying economic mechanism developed by Borjas $(1987,1991){ }^{6}$

We now consider how earnings potential at home, $\theta_{0}$, of migrants differs from the population mean $\mu_{0}$. From the normality assumption we obtain

$$
\begin{aligned}
E\left(\theta_{0} \mid \text { Migrate }=1\right) & =E\left(\theta_{0} \mid \theta_{1}+\epsilon_{1}>\theta_{0}+\epsilon_{0}+c\right) \\
& =\mu_{0}+\left(\rho_{\theta}-\frac{\sigma_{\theta_{0}}}{\sigma_{\theta_{1}}}\right) \frac{\sigma_{\theta_{0}} \sigma_{\theta_{1}}}{\sigma_{v}} \frac{\phi(z)}{1-\Phi(z)},
\end{aligned}
$$

\footnotetext{
${ }^{6}$ Borjas (1987) develops the original model focusing on the role of unobservables. In the formulation here, this corresponds to the case of $\sigma_{\theta_{0}}=\sigma_{\theta_{1}}=0$. Borjas (1991) introduces the distinction between returns to observables and unobservables, focusing on the case where observable skills are perfectly correlated across countries $\left(\operatorname{corr}\left(\theta_{0}, \theta_{1}\right)=1\right)$.
} 
where $v=\theta_{1}+\epsilon_{1}-\theta_{0}-\epsilon_{0}$ is the earnings difference between abroad and home that has variance $\sigma_{v}^{2}=\operatorname{var}(v) . z=\frac{\mu_{0}+c-\mu_{1}}{\sigma_{v}}$ is a constant reflecting differences in means across destinations, adjusted for migration costs and normalized by the variance of the earnings difference. In our empirical analysis, we investigate how selection on observables relates to relative inequality $\left(\frac{\sigma_{\theta_{0}}}{\sigma_{\theta_{1}}}\right)$ between the two destinations. In addition to relative inequality, the theoretical prediction on selection depends on the cross-country correlation in the observed component $\left(\rho_{\theta}\right)$. A situation where $\rho_{\theta}$ is sufficiently high provides a natural benchmark case because we analyze migration flows between industrialized countries. ${ }^{7}$ If the potential destination is less equal than home $\left(\sigma_{\theta_{1}}>\sigma_{\theta_{0}}\right)$, migrants will be positively selected: $E\left(\theta_{0} \mid\right.$ Migrate $\left.=1\right)>\mu_{0}$. Intuitively, the positively selected migrants benefit from the upside opportunities in less equal countries. If the potential destination country is more equal $\left(\sigma_{\theta_{1}}<\sigma_{\theta_{0}}\right)$, migrants will be negatively selected: $E\left(\theta_{0} \mid\right.$ Migrate $\left.=1\right)<\mu_{0}$. Intuitively, the negatively selected migrants benefit from the insurance of a compressed wage distribution.

The model emphasizes the role of inequality for the selection of migrants. Differences in mean earnings across home and abroad have strong effects on migration probabilities (and appear in the term $z$ above), but they have no effect on the direction of selection.

Borjas (1991) extends the model to include stochastic migration costs - an approach that leads to very similar results as long as the migration costs are unrelated to potential earnings; Chiquiar and Hanson (2005) emphasize that selection patterns can change substantially when migration costs vary systematically with earnings potential. Because we are focusing on the population of high-skilled individuals who migrate from an advanced country to other advanced countries, differential migration costs are presumably less important for them than for lower-skilled migrants who, e.g., migrate from Mexico to the United States.

\subsection{Empirical Evidence on the Roy/Borjas Model}

While we are not aware of other papers that focus on the role of inequality for the selection of high-skilled migrants, a large number of papers analyze the effect of inequality on migrant selection in general. The empirical evidence on the predictions of the basic Roy/Borjas model is mixed (see Table 1).

Existing papers use different skill measures to analyze the selection of migrants. Starting with Borjas (1987), a number of papers use earnings to measure migrant selection. The pattern of selection in terms of earnings is mostly consistent with

\footnotetext{
${ }^{7}$ This rules out the case of 'refugee sorting' (Borjas 1987).
} 


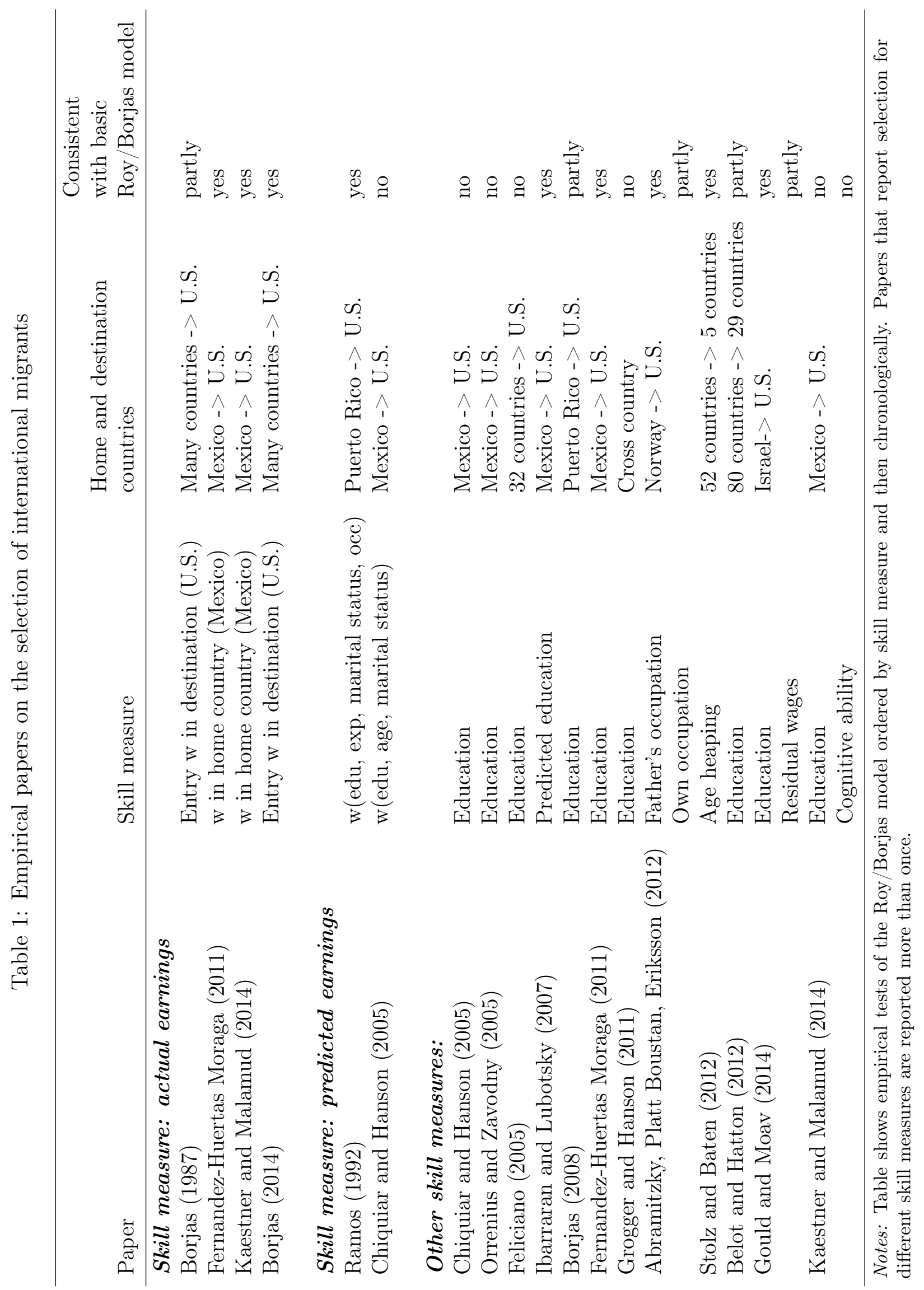


the prediction of the basic model. In the United States, migrants from more equal home countries have lower earnings than migrants from less equal countries (Borjas, 1987, 2014). Migrants from Mexico to the United States (a more equal country than Mexico) have lower earnings than non-migrants (Fernández-Huertas Moraga, 2011, Kaestner and Malamud, 2014).

Other papers use predicted earnings to measure selection. While predicted earnings indicate that the selection of migrants from Puerto Rico to the United States (a more equal country than Puerto Rico) is consistent with the basic Roy/Borjas model (Ramos, 1992), the selection of migrants from Mexico to the United States is not consistent with the basic model (Chiquiar and Hanson, 2005). In their seminal paper on the migration of Mexicans to the United States, Chiquiar and Hanson show that a model with skill-varying migration costs is a better description of the migration from Mexico to the United States. ${ }^{8}$

Lastly, a number of papers have used skill measures based on a single covariate (e.g. education or occupation) to measure migrant selection. Some of these papers find that migrant selection is consistent with the predictions of the basic Roy/Borjas model (e.g. Ibarraran and Lubotsky, 2007, Abramitzky et al., 2012, Stolz and Baten, 2012, Gould and Moav, 2014), while other papers find that selection is only partly consistent with the basic model (Borjas, 2008, Belot and Hatton, 2012), and yet others find selection that is not consistent with the basic model (Chiquiar and Hanson, 2005, Orrenius and Zavodny, 2005, Feliciano, 2005, Grogger and Hanson, 2011, Kaestner and Malamud, 2014). Many papers that investigate selection based on single characteristics often confirm the predictions of the basic Roy/Borjas model for some skill measures but reject the predictions for other measures. In our analysis below, we decompose selection patterns and show that selection does not need to be uniform across characteristics. ${ }^{9}$

\footnotetext{
${ }^{8}$ The selection of Mexican migrants to the United States is hotly disputed in the literature. While some papers find evidence for negative selection that is consistent with the basic Roy/Borjas model (e.g. Ibarraran and Lubotsky, 2007, Fernández-Huertas Moraga, 2011, Kaestner and Malamud, 2014 for some characteristics), other papers find intermediate selection that suggests that migration costs vary with skills, perhaps driven by poverty constraints (Chiquiar and Hanson, 2005, Orrenius and Zavodny, 2005, Kaestner and Malamud, 2014 for other characteristics).

${ }^{9}$ In addition to the selection of international migrants, which we focus on in this paper, a number of papers investigate the Roy/Borjas applied to internal migration, including Borjas et al. (1992) and Bartolucci et al. (2014).
} 


\section{Data}

\subsection{University Graduates}

We analyze the selection of high-skilled migrants using survey data on university graduates collected by the German Centre for Research on Higher Education and Science Studies (DZHW). These are nationally representative longitudinal surveys of individuals who complete their university education in Germany (Grotheer et al., 2012). ${ }^{10}$ The DZHW sampled university graduates from the graduation cohorts 1993, 1997, 2001, and 2005. ${ }^{11}$ Graduates in each cohort are surveyed twice. The initial survey takes place about 12 months after graduation. The same individuals participate in a follow-up survey about five years after graduation (Figure A.1). ${ }^{12}$ The survey is ideal for our purposes because graduates are surveyed even if they move abroad. We focus our analysis on migration decisions that are measured five years after graduation. ${ }^{13}$ Five years after graduation, the total number of respondents is 6,737 (1993 cohort), 6,220 (1997 cohort), 5,426 (2001 cohort), and 6,459 (2005 cohort). To analyze selection of high-skilled migrants, we focus on graduates from traditional universities. ${ }^{14}$ Furthermore, we restrict the sample to full-time workers with information on all key characteristics.

The graduate data contain detailed information on graduates' personal characteristics, family background, study history, and labor market experience (Table 2). In our data, 45 percent of graduates are female, 78 percent live with a partner, 42 percent are married, and 29 percent have children. The graduates' mothers have about 13.5 years of education, and their fathers have about 14.9 years of education on average. Most mothers and fathers have worked as salaried employees. Grad-

\footnotetext{
${ }^{10}$ Between 1993 and 2005, the majority of German university graduates completed degrees called Diplom, Magister, or Staatsexamen. These degrees usually last between four and six years and are considered comparable to a master's degree in other countries.

${ }^{11}$ The respondents graduated during the academic years 1992-93, 1996-97, 2000-01, and 2004-05.

${ }^{12}$ To ensure that the data collected are representative for the examined population, the DZHW Graduate Panel Surveys are based on a multiply stratified cluster sampling, with fields of study, degree types, and universities as strata (Grotheer et al., 2012). Response rates to the initial surveys range between 30 and 40 percent. We analyze differences in response rates between the initial survey and the follow-up survey according to migration status reported in the initial survey. The follow-up survey response rate for graduates who have responded in the initial survey is 66 percent for graduates who worked in Germany one year after graduation and 59 percent for graduates who worked abroad.

${ }^{13}$ After graduation, many university graduates enroll in additional training such as legal or teacher trainee-ships (Referendariat), or PhD programs. Earnings in the initial survey are thus a noisy measure of earnings potential.

${ }^{14}$ The German higher education sector consists of traditional universities, universities of applied sciences (Fachhochschulen), specialized universities focusing on arts, music, or theology, and a very small number of private universities. The best students tend to enroll in traditional universities, but universities of applied sciences have improved in reputation and quality in recent decades.
} 
uates have completed university with an average grade of 2.02. (The top grade is 1.0 and the worst passing grade is 4.0.) About 7.8 percent have studied abroad but returned to graduate in Germany. ${ }^{15}$ Two thirds (66 percent) have studied in the federal state where they graduated from high school. Their average high school grade (Abitur) was 2.11. About 22 percent had completed an apprenticeship before starting their degree. Five years after graduation, 19.1 percent have completed a $\mathrm{PhD}$, and 7.3 percent have completed further non-PhD level studies (such as MBAs). Average earnings were 43,491 Euros (in 2001 prices). ${ }^{16}$ In addition to the variables summarized in Table 2, we also have detailed information on a student's university and field of study.

Five years after graduation, about 5.2 percent of graduates work abroad. The main destinations are Switzerland (152 graduates), the United States (87 graduates), the UK (68 graduates), Austria (42 graduates), and France (41 graduates) (Table $3)$.

\subsection{Earnings Inequality Data}

We classify destination countries as either more or less equal than Germany using newly constructed measures of earnings inequality for university graduates. Existing inequality measures, such as Gini coefficients, typically measure inequality for the whole population, but the decisions of high-skilled migrants will likely depend on earnings inequality of university graduates.

Our main data source is the Luxembourg Income Study (LIS) (2013). The LIS provides access to individual-level earnings surveys from several countries and years. We use all available surveys for the main destinations of German university graduates. Two important destinations of German university graduates, Austria and Switzerland, are not comprehensively covered in the LIS. We therefore augment the LIS data with additional data from both the Microcensus (1999) and the European Union Statistics on Income and Living Conditions (EU-SILC, 2007 and 2008) for Austria, and with data from the Swiss Labour Force Survey (Schweizerische Arbeitskräfteerhebung, SAKE, 1998-2005) for Switzerland.

To measure earnings inequality for high-skilled individuals, we restrict the samples in the individual-level surveys to university graduates. We further restrict the samples to full-time employees between 30 and 60 years of age, and we exclude individuals who are self-employed, enrolled in educational institutions, or who report negative earnings.

\footnotetext{
${ }^{15}$ The surveys do not sample individuals who complete their studies outside Germany.

${ }^{16}$ This corresponds to around 79,084 U.S. dollars in 2014 prices.
} 
Table 2: Summary statistics for German university graduates

\begin{tabular}{|c|c|c|c|c|c|}
\hline & \multicolumn{2}{|c|}{ Full sample } & \multirow{2}{*}{$\begin{array}{c}\begin{array}{c}\text { Working } \\
\text { in Germany }\end{array} \\
\text { Mean }\end{array}$} & \multirow{2}{*}{$\begin{array}{c}\begin{array}{c}\text { Abroad } \\
\text { more equal }\end{array} \\
\text { Mean }\end{array}$} & \multirow{2}{*}{$\begin{array}{c}\begin{array}{c}\text { Abroad } \\
\text { less equa }\end{array} \\
\text { Mean }\end{array}$} \\
\hline & Mean & $\mathrm{SD}$ & & & \\
\hline \multicolumn{6}{|l|}{ Job characteristics (after five years) } \\
\hline Working abroad & 0.052 & - & 0 & 1 & 1 \\
\hline Income in Euro (2001 prices) & 43,491 & 19,334 & 43,265 & 39,458 & 49,231 \\
\hline \multicolumn{6}{|l|}{ Education after first degree } \\
\hline $\mathrm{PhD}$ completed & 0.191 & - & 0.182 & 0.313 & 0.371 \\
\hline Further studies completed & 0.073 & - & 0.071 & 0.125 & 0.122 \\
\hline \multicolumn{6}{|l|}{ Education first degree } \\
\hline Final university grade & 2.018 & 0.681 & 2.032 & 1.698 & 1.787 \\
\hline Studying abroad & 0.078 & - & 0.072 & 0.240 & 0.169 \\
\hline ERASMUS/Total students in subject & 0.040 & 0.057 & 0.039 & 0.052 & 0.050 \\
\hline \multicolumn{6}{|l|}{ Education before first degree } \\
\hline Studying in same state as high school & 0.659 & - & 0.663 & 0.583 & 0.581 \\
\hline Final school grade & 2.110 & 0.639 & 2.119 & 1.951 & 1.959 \\
\hline Apprenticeship & 0.220 & - & 0.225 & 0.094 & 0.138 \\
\hline \multicolumn{6}{|l|}{ Personal characteristics } \\
\hline Female & 0.445 & - & 0.444 & 0.594 & 0.445 \\
\hline Partner & 0.780 & - & 0.782 & 0.740 & 0.736 \\
\hline Married & 0.416 & - & 0.421 & 0.281 & 0.344 \\
\hline Any children & 0.291 & - & 0.297 & 0.156 & 0.184 \\
\hline \multicolumn{6}{|l|}{ Parental background } \\
\hline Mother's education (years) & 13.459 & 3.102 & 13.423 & 14.458 & 14.035 \\
\hline Father's education (years) & 14.852 & 3.065 & 14.816 & 15.458 & 15.493 \\
\hline Mother self-employed & 0.092 & - & 0.093 & 0.063 & 0.091 \\
\hline Mother salaried employee & 0.597 & - & 0.596 & 0.677 & 0.619 \\
\hline Mother civil servant & 0.108 & - & 0.105 & 0.177 & 0.148 \\
\hline Mother worker & 0.100 & - & 0.103 & 0.042 & 0.049 \\
\hline Mother did not work & 0.103 & - & 0.104 & 0.041 & 0.093 \\
\hline Father self-employed & 0.194 & - & 0.191 & 0.188 & 0.262 \\
\hline Father salaried employee & 0.447 & - & 0.448 & 0.479 & 0.406 \\
\hline Father civil servant & 0.223 & - & 0.221 & 0.271 & 0.258 \\
\hline Father worker & 0.113 & - & 0.116 & 0.063 & 0.062 \\
\hline Father did not work & 0.023 & - & 0.024 & 0.000 & 0.012 \\
\hline Observations & 11,091 & & 10,510 & 96 & 485 \\
\hline
\end{tabular}

Notes: The table shows summary statistics of German university graduates at five years after graduation. Information on earnings is available for 10,315 of the 11,091 graduates.

Based on the individual-level surveys, we construct earnings percentiles for each country and available year using the survey sampling weights (see Appendix Table A.1 for available survey years in each country). Some surveys in the (augmented) LIS data report gross earnings, while others report net earnings. To measure crosscountry inequality of net earnings, we convert gross into net earnings using the net personal average tax rate ${ }^{17}$ of single persons without children from the OECD (2013c)..$^{18}$ The data appendix provides more detail on the construction of the in-

\footnotetext{
${ }^{17}$ The net personal average tax rate is defined as the personal income tax and employee social security contributions net of cash benefits, expressed as a percentage of gross wage earnings.

${ }^{18}$ The OECD reports three different tax rates along the earnings distribution: the average tax
} 
Table 3: Destinations of German university graduates

\begin{tabular}{lcc}
\hline Country & Number of graduates & Wage inequality data \\
\hline Germany & 10,510 & Yes \\
Switzerland & 152 & Yes \\
United States & 87 & Yes \\
UK & 68 & Yes \\
Austria & 42 & Yes \\
France & 41 & Yes \\
Luxembourg & 25 & Yes \\
Netherlands & 25 & Yes \\
Spain & 20 & Yes \\
Belgium & 20 & Yes \\
Norway & 20 & Yes \\
Sweden & 15 & Yes \\
Italy & 13 & Yes \\
Denmark & 13 & Yes \\
Ireland & 11 & Yes \\
China & 8 & No \\
Australia & 7 & Yes \\
Canada & 7 & Yes \\
Japan & 5 & Yes \\
Finland & 5 & Yes \\
Poland & 5 & Yes \\
Brazil & 5 & No \\
New Zealand & 5 & No \\
Other & 56 & No \\
\hline
\end{tabular}

Notes: The table shows the most important destinations of German university graduates in the graduate survey data and the availability of inequality data for university graduates in the augmented LIS data. All destinations in the category 'Other' receive less than five graduates.

equality measures.

In our main analysis, we use the ratio of the 75 th to the 25 th earnings percentile (75/25 ratio) for university graduates to measure earnings inequality across countries. Figure 1 shows the ranking of countries according to the $75 / 25$ ratio that we average over 1998 to 2010 to reflect the years that correspond to our graduate surveys. (Appendix Table A.2 reports 75/25 ratios for each country.) Inequality is highest in the United States, followed by France and Poland. The Scandinavian countries and Australia are most equal. Germany is ranked in the middle. ${ }^{19}$ We can

rate at 67 percent, at 100 percent, and at 167 percent of average earnings. We apply the tax rate at 67 percent of average earnings to the 25th percentile and below, the tax rate at 100 percent of average earnings to earnings between the 25 th and the 75 th percentile, and the tax rate at 167 percent of average earnings to the 75 th percentile and above.

${ }^{19}$ Recent papers have documented the rise in German earnings inequality during the last decades (Dustmann et al., 2009, Card et al., 2013). These papers have used large administrative datasets to measure inequality. In these datasets, earnings are censored at the maximum of social security contributions. Regarding individuals with a university education, about 42 percent of observations for males and 13 percent of observations for females are top coded between 1998 and 2008. As we need to measure inequality for university graduates who are in the top 11 percent of the educational distribution, we prefer to use earnings surveys in the LIS that are not top-coded. 
therefore investigate the selection of German university graduates into less equal and into more equal countries. ${ }^{20}$

\subsection{Data on ERASMUS Places}

We use data on the number of ERASMUS places to correct for potential selection bias in the augmented Mincer regression. ERASMUS, the largest student exchange program in Europe, facilitates studying abroad for one or two semesters at another European university. The program started in 1987 and has expanded massively since then. The expansion of the program increased German students' study abroad opportunities, which depend on the year a department joined the program and on how much a department expanded the number of places over time (for details see Parey and Waldinger, 2011). The German Academic Exchange Service (DAAD) provided us with data on the number of study abroad places in the ERASMUS program in each university, subject, and year. The median student studies abroad for one or two semesters about three years before graduation. We assign the number of ERASMUS places in the corresponding academic year, subject, and university to each student. To account for differences in cohort size that affect students' study abroad opportunities, we normalize the number of ERASMUS places with the number of students in the corresponding university and subject. ${ }^{21}$

\section{Method and Results}

\subsection{The Selection of Migrants to More and to Less Equal Destinations}

For our analysis, we use predicted earnings to measure earnings potential in the home country. This measure of skill represents $\theta_{0}$ in the model outlined above. We then use predicted earnings to compare the distribution of skills of migrants to less equal countries, of migrants to more equal countries, and of non-migrants.

To construct predicted earnings, we estimate an augmented Mincer regression

\footnotetext{
${ }^{20}$ As we measure selection with predicted earnings, an ideal measure of inequality would be based on country-level differences of returns to observed skills. Such a measure would require graduate datasets with comparable characteristics on each graduate for all major destinations. As these are not available, we use the $75 / 25$ ratio that is based on actual earnings. The empirical results are valid as long as countries with higher $75 / 25$ ratios also exhibit higher returns to observed skills.

${ }^{21}$ We use the number of first year students in each university and subject in the academic year 1992/1993 for this normalization. The data come from the German Statistical Office.
} 
for non-migrants only:

$$
\log w_{0 i}=X_{0 i} \beta_{0}+\varepsilon_{0 i}
$$

The estimate of $\beta_{0}$ measures returns to skills in the home country. Our data allow us to include a large number of variables $X_{i}$ to obtain a good prediction of earnings potential. $X_{i}$ contains variables that measure personal characteristics (gender, marital/partnership status, children), parental background (mother's and father's education and occupation), additional education after graduation (completing a PhD or a non-PhD graduate degree), university experience (final university grade, age at graduation, an indicator for completing university with a bachelor's degree, 24 subject fixed effects, as well as university fixed effects), pre-university education (final high-school grade and an indicator for completing an apprenticeship before studying), previous mobility (an indicator for moving state between high school and university), and other control variables (potential labor market experience and graduate cohort fixed effects). The coefficients of the augmented Mincer regression have the expected signs and magnitudes (Table 4, column 1). ${ }^{22}$ The $R^{2}$ of about 0.28 is high for a Mincer regression, suggesting that predicted earnings are an informative skill measure for university graduates.

Next, we predict potential earnings in the home country for migrants and for nonmigrants. The predictions are based on the coefficient vector $\left(\hat{\beta}_{0}\right)$ and on individual characteristics $X_{i}{ }^{23}$

$$
\hat{\theta}_{0 i}=X_{i} \hat{\beta}_{0}
$$

We then use this measure of skills to compare three groups of interest: migrants to less equal countries, migrants to more equal countries, and non-migrants. Specifically, we construct Cumulative Distribution Functions (CDFs) of predicted earnings $\hat{\theta}_{0}$ by migration group:

$$
F\left(\hat{\theta}_{0} \mid \text { Migration status }\right)
$$

and plot them in Figure 2(a). The dashed line is the CDF of non-migrants. The dark, solid line is the CDF of migrants to less equal destinations, such as the United States. This CDF lies to the right of the CDF for non-migrants, indicating that this

\footnotetext{
${ }^{22}$ Because all graduates are surveyed around five years after graduation, the variation in potential labor market experience is small and estimated coefficients are different from the typical pattern observed in Mincer regressions.

${ }^{23}$ Potential earnings are predicted for all individuals with non-missing characteristics $X_{i}$, independently of whether they report earnings. Alternatively, one could exclude individuals who do not report earnings from the prediction. Results for this alternative sample are very similar to the results presented below.
} 
Table 4: Augmented Mincer regression for university graduates in Germany

\begin{tabular}{|c|c|c|c|c|c|c|}
\hline & \multicolumn{2}{|c|}{$(1)$} & \multicolumn{2}{|c|}{$(2)$} & \multicolumn{2}{|c|}{$(3)$} \\
\hline \multirow[t]{3}{*}{ Dependent variable } & \multicolumn{2}{|c|}{ Labor earnings } & \multicolumn{2}{|c|}{ Labor earnings } & \multicolumn{2}{|c|}{ Working in Germany } \\
\hline & \multicolumn{2}{|c|}{ OLS } & \multicolumn{2}{|c|}{ Heckman sel. model } & \multicolumn{2}{|c|}{ Selection equation } \\
\hline & Coeff. & s.e. & Coeff. & s.e. & Coeff. & s.e. \\
\hline \multicolumn{7}{|l|}{ Personal } \\
\hline Female & $-0.131^{* * *}$ & $(0.008)$ & $-0.131^{* * *}$ & $(0.008)$ & -0.047 & $(0.053)$ \\
\hline Partner & $0.066^{* * *}$ & $(0.009)$ & $0.065^{* * *}$ & $(0.009)$ & 0.070 & $(0.058)$ \\
\hline Married (additionally) & $0.028^{* * *}$ & $(0.009)$ & $0.028^{* * *}$ & $(0.009)$ & 0.027 & $(0.058)$ \\
\hline Children & $-0.040 * * *$ & $(0.009)$ & $-0.041^{* * *}$ & $(0.010)$ & $0.210^{* * *}$ & $(0.065)$ \\
\hline \multicolumn{7}{|l|}{ Postgraduate education } \\
\hline PhD completed & -0.003 & $(0.011)$ & 0.000 & $(0.013)$ & $-0.367 * * *$ & $(0.065)$ \\
\hline Further degree (non-PhD) & -0.024 & $(0.015)$ & -0.021 & $(0.016)$ & $-0.251^{* * *}$ & $(0.085)$ \\
\hline \multicolumn{7}{|l|}{ University career } \\
\hline Final grade & $0.048^{*}$ & $(0.027)$ & $0.046^{*}$ & $(0.027)$ & 0.079 & $(0.203)$ \\
\hline Final grade square & $-0.023^{* * *}$ & $(0.006)$ & $-0.023^{* * *}$ & $(0.006)$ & -0.007 & $(0.048)$ \\
\hline Bachelor's degree & $-0.131^{* * *}$ & $(0.028)$ & $-0.132^{* * *}$ & $(0.028)$ & 0.049 & $(0.158)$ \\
\hline Age at end of studies & $-0.026^{* *}$ & $(0.011)$ & $-0.026^{* *}$ & $(0.011)$ & -0.013 & $(0.097)$ \\
\hline Age square & $0.000^{*}$ & $(0.000)$ & $0.000^{*}$ & $(0.000)$ & 0.001 & $(0.002)$ \\
\hline \multicolumn{7}{|l|}{ Pre-university education } \\
\hline School grade & -0.041 & $(0.034)$ & -0.043 & $(0.034)$ & 0.109 & $(0.224)$ \\
\hline School grade square & 0.009 & $(0.008)$ & 0.010 & $(0.008)$ & -0.011 & $(0.052)$ \\
\hline Apprenticeship & $0.037 * * *$ & $(0.010)$ & $0.037^{* * *}$ & $(0.010)$ & 0.078 & $(0.071)$ \\
\hline \multicolumn{7}{|l|}{ Previous mobility } \\
\hline \multicolumn{7}{|l|}{ Parental background } \\
\hline Mother's education (years) & $0.003^{*}$ & $(0.002)$ & $0.003^{*}$ & $(0.002)$ & -0.002 & $(0.010)$ \\
\hline Father's education (years) & $0.003^{*}$ & $(0.002)$ & $0.003^{*}$ & $(0.002)$ & $-0.019 *$ & $(0.010)$ \\
\hline Mother self-employed & -0.008 & $(0.017)$ & -0.009 & $(0.017)$ & 0.107 & $(0.112)$ \\
\hline Mother salaried empl. & -0.012 & $(0.013)$ & -0.012 & $(0.013)$ & 0.010 & $(0.086)$ \\
\hline Mother civil servant & -0.019 & $(0.018)$ & -0.019 & $(0.017)$ & -0.013 & $(0.112)$ \\
\hline Mother worker & -0.001 & $(0.016)$ & -0.003 & $(0.016)$ & 0.194 & $(0.122)$ \\
\hline Father self-employed & $0.054^{* *}$ & $(0.025)$ & $0.056^{* *}$ & $(0.025)$ & -0.260 & $(0.195)$ \\
\hline Father salaried empl. & $0.041^{*}$ & $(0.024)$ & $0.041^{*}$ & $(0.024)$ & -0.053 & $(0.192)$ \\
\hline Father civil servant & 0.027 & $(0.025)$ & 0.028 & $(0.025)$ & -0.132 & $(0.196)$ \\
\hline Father worker & 0.003 & $(0.026)$ & 0.003 & $(0.026)$ & 0.009 & $(0.209)$ \\
\hline \multicolumn{7}{|l|}{ Experience } \\
\hline Experience in months & $-0.058 * * *$ & $(0.022)$ & $-0.059 * * *$ & $(0.022)$ & 0.096 & $(0.138)$ \\
\hline Experience square & $0.000^{* * *}$ & $(0.000)$ & $0.000^{* * *}$ & $(0.000)$ & -0.001 & $(0.001)$ \\
\hline \multicolumn{3}{|l|}{ ERASMUS places/students } & & & $-1.197^{* * *}$ & $(0.424)$ \\
\hline \multicolumn{3}{|l|}{ Mills ratio } & -0.050 & $(0.095)$ & & \\
\hline Graduate cohort FE & \multicolumn{2}{|l|}{ YES } & \multicolumn{2}{|l|}{ YES } & \multicolumn{2}{|l|}{ YES } \\
\hline Subject FE & \multicolumn{2}{|l|}{ YES } & \multicolumn{2}{|l|}{ YES } & YES & \\
\hline University FE & YES & & YES & & YES & \\
\hline R-sq./Pseudo R-sq. & 0.282 & & & & 0.132 & \\
\hline Observations & 9,778 & & 9,778 & & 10,315 & \\
\hline
\end{tabular}

Notes: Column (1) reports results from the augmented Mincer regression. Column (2) reports results from the augmented Mincer regression that controls for selection in the decision to work in Germany using a Heckman selection correction. Column (3) reports the corresponding selection equation, which predicts working in Germany with the number of ERASMUS places normalized by the cohort size in a graduate's university department. Significance levels: *** $\mathrm{p}<0.01,{ }^{* *} \mathrm{p}<0.05,{ }^{*} \mathrm{p}<0.1$. 
Figure 2: Predicted earnings of migrants and non-migrants - three groups of countries

\section{(a) $\mathrm{CDF}$}

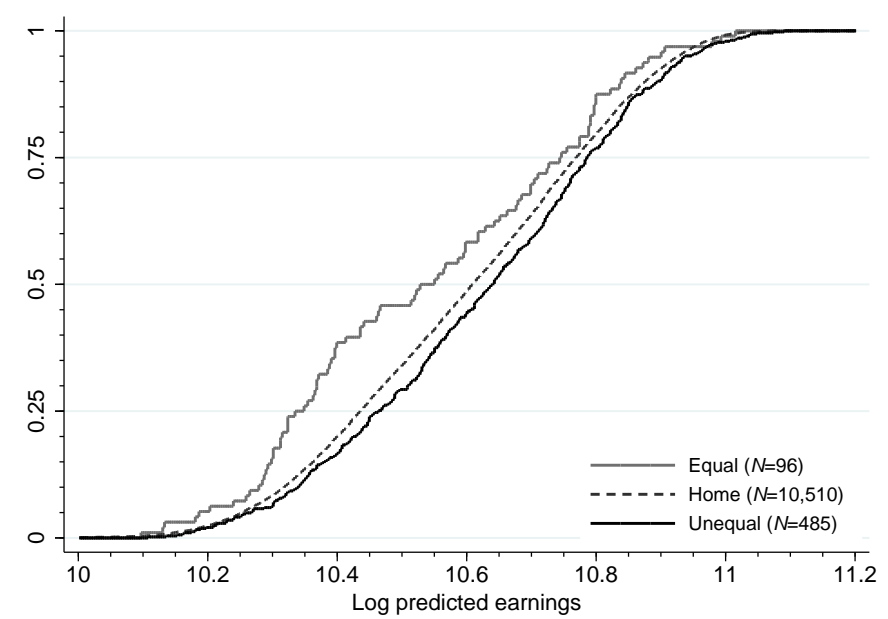

(b) CDF - smoothed

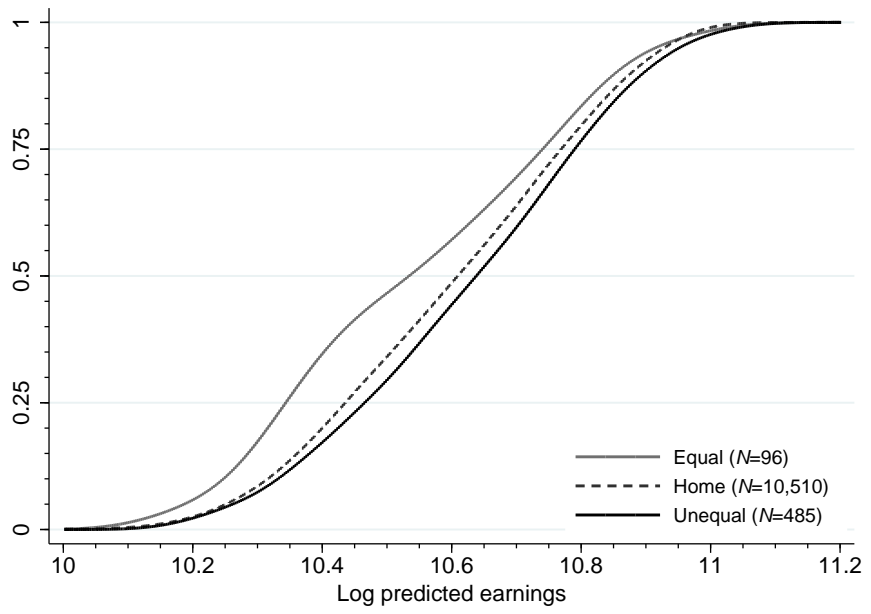

Notes: Panel (a) shows CDFs of predicted earnings (prediction based on returns reported in column (1) of Table 4) for three groups: migrants to more equal countries, non-migrants, and migrants to less equal countries. Panel (b) shows a kernel smoothed version of the CDFs.

group is positively selected in terms of earnings potential. The migrants to unequal countries have skills which, according to the returns in the Mincer regression, are valued more highly than those of non-migrants: median log predicted earnings for these migrants are 10.65 (compared to 10.61 for non-migrants), with a lower quartile of 10.47 (non-migrants: 10.44) and an upper quartile of 10.80 (non-migrants: 10.77). The CDFs of non-migrants and of migrants to less equal countries do not cross, indicating that these migrants are positively selected over the full range of predicted 
earnings. ${ }^{24}$

The lighter, solid line is the CDF of migrants to more equal destinations, such as Sweden. It indicates that migrants to more equal countries are negatively selected relative to non-migrants. Median log predicted earnings for these migrants are 10.56 (compared to 10.61 for non-migrants), with a lower quartile of 10.36 (non-migrants: 10.44) and an upper quartile of 10.75 (non-migrants: 10.77). The differences between the CDFs are substantial and in the same order of magnitude as standard estimates for the returns to an additional year of education in the United States (Card, 1999).

Since our sample includes relatively few migrants, in particular to more equal destinations, we also present a smoothed version of the CDFs using a kernel smoothing approach (Figure 2(b)). ${ }^{25}$

Inequality varies in potential destination countries. We use this variation to analyze selection to countries with more extreme levels of (in)equality by splitting more and less equal countries into two groups each. Thus, we now compare five types of destinations: very unequal, somewhat unequal, home, somewhat equal, and very equal countries. We classify the three countries with the most unequal earnings distribution as very unequal, and the three countries with the most equal distribution as very equal. Results are shown in Figure 3. Very unequal countries receive the most positively selected migrants; somewhat unequal countries receive somewhat positively selected migrants; somewhat equal countries receive slightly negatively selected migrants; and very equal countries receive strongly negatively selected migrants. The CDFs are somewhat noisier than in the previous graphs because sample sizes of migrants are relatively small, especially for equal countries. Nonetheless, the selection pattern follows the theoretical predictions for the five groups.

\subsection{Controlling for Selection in the Augmented Mincer Re- gression}

As our previous analysis has shown, observable characteristics indicate that migrants and non-migrants have different predicted earnings. Unless this selection is fully accounted for by the observables, the selection could potentially bias the coefficients of the augmented Mincer regression and thus our measure of predicted earnings. We

\footnotetext{
${ }^{24}$ We test the statistical significance of our findings in section 3.3 .

${ }^{25}$ Smoothed CDFs are based on the Gaussian kernel. We choose the bandwidth separately for each migrant group to account for the differences in the corresponding sample sizes. Bandwidth is chosen according to Silverman's rule of thumb (Silverman, 1986, p. 48), which we then rescale with a factor of 0.6 to avoid over-smoothing.
} 
Figure 3: Predicted earnings of migrants and non-migrants - five groups of countries

(a) $\mathrm{CDF}$

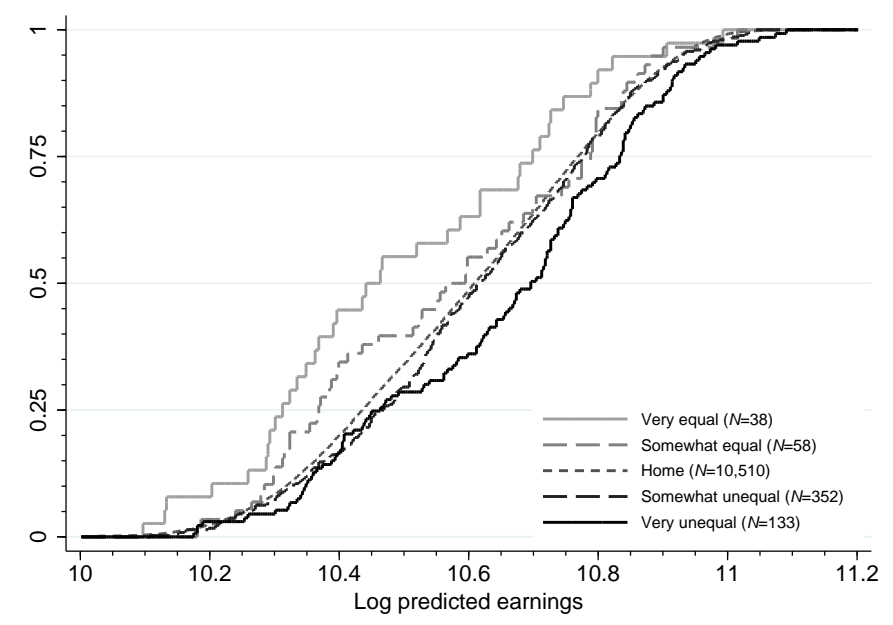

(b) CDF - smoothed

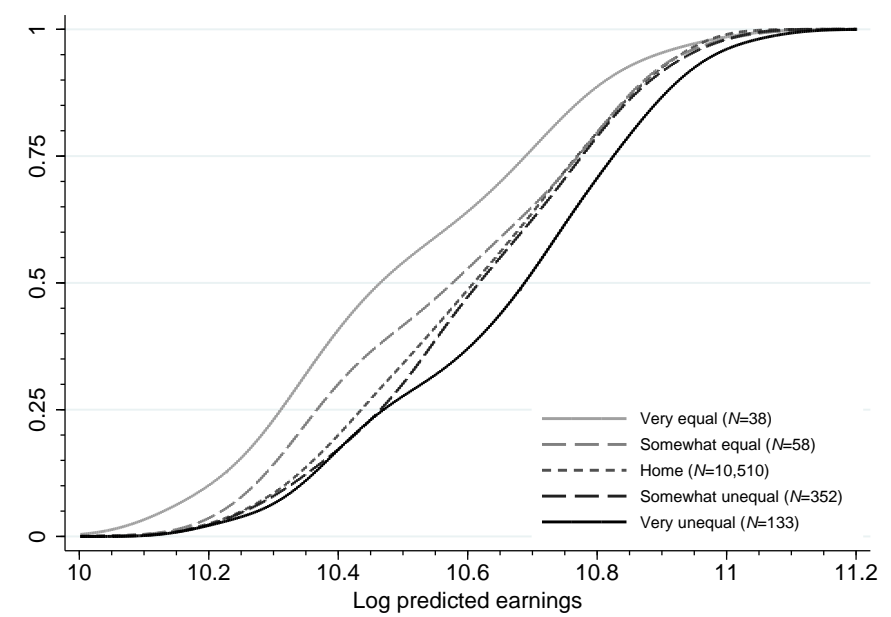

Notes: Panel (a) shows CDFs of predicted earnings (prediction based on returns reported in column (1) of Table 4) for five groups: migrants to very equal countries, migrants to somewhat equal countries, non-migrants, migrants to somewhat unequal countries, and migrants to very unequal countries. Panel (b) shows a kernel smoothed version of the CDFs.

use a Heckman selection procedure to control for this potential selection.

We control for selection in the Mincer regression by estimating a selection equation that predicts whether a graduate works in Germany or migrates abroad. To predict whether graduates work in Germany, we use the introduction and expansion of the ERASMUS student exchange program as an instrumental variable. The ERASMUS program allows students to study abroad for one or two semesters before they continue their studies in Germany. The program was introduced in 1987 and 
increased massively since then. In Germany, about 4,925 students participated in ERASMUS in 1990 (the year when the typical student of the 1993 cohort studied abroad) and participation rose to 18,482 in 2002 (the year when the typical student of the 2005 graduate cohort studied abroad). The program was introduced at different times and expanded at varying rates, depending on the university and department. Previous work has shown that the introduction and expansion of the ERASMUS program not only increases the probability that students study abroad but also the probability of working abroad after graduation (Parey and Waldinger, 2011).

In our selection equation, we predict whether individuals work in Germany with a measure of ERASMUS scholarship places (normalized by the number of students) in a graduate's university department. This instrument will be valid if the number of ERASMUS places in a student's university can be excluded from the wage regression. Conditional on the controls in the Mincer regression, and in particular controlling for university and subject fixed effects, the number of ERASMUS scholarship places should not have a direct effect on wages. ${ }^{26}$ Crucially, we do not use the actual decision of studying abroad but the availability of department-level ERASMUS scholarship places, which predict studying abroad and working abroad later on, to instrument for working in Germany. ${ }^{27}$

Column (3) of Table 4 shows the first stage estimates. Consistent with the findings in Parey and Waldinger (2011), the availability of ERASMUS significantly lowers the probability of working in Germany. Coefficients on the control variables also have the expected signs.

Column (2) in Table 4 shows that controlling for selection in the Mincer regression only has a small effect on the estimated coefficients. In addition to the rich set of observables, this reflects that the share of graduates not migrating (and thus observed in our Mincer regression) is very high, and that selection of migrants occurs both at the top and the bottom of the distribution. The coefficient on the Mills ratio is therefore quantitatively small and insignificant. The resulting CDFs of

\footnotetext{
${ }^{26}$ Parey and Waldinger (2011) discuss the exclusion restriction of the ERASMUS instrument in more detail. They show that the expansion of ERASMUS in a department is not correlated with a wider push to increase the international outlook of students and that the probability of studying abroad only increases once ERASMUS has been introduced. Hence, there are no pre-trends in studying abroad before the introduction of ERASMUS.

${ }^{27}$ As discussed in more detail in Parey and Waldinger (2011), students had only limited knowledge of the number of ERASMUS places at the time of enrollment and it is unlikely that they chose to study in a particular university to benefit from larger increases in the number of ERASMUS places. Better universities usually offer more ERASMUS places. Because we rely on the variation in the number of ERASMUS places over time and control for university fixed effects, this will not affect the estimation of our selection equation.
} 
earnings potential by migration status are presented in Figure 4 . They confirm that migrants to less equal destinations are positively selected, while migrants to more equal destinations are negatively selected.

\subsection{Tests for Stochastic Dominance}

We investigate the statistical significance of the substantial differences between the CDFs with tests for first-order stochastic dominance. As we estimate the Mincer earnings equation in the first step of our analysis and construct predicted earnings based on the Mincer regression, we need to account for this additional source of uncertainty when we compute the $p$-values. We therefore apply the bootstrap procedure for stochastic dominance tests developed in Barrett and Donald (2003). ${ }^{28} \mathrm{We}$ also report $p$-values from conventional Kolmogorov-Smirnov tests, which do not account for the uncertainty associated with the estimation of parameters in the Mincer regression.

The corresponding test results are shown in Table 5. The top row of Panel A1 indicates that we can reject the null hypothesis that the more-equal-CDF dominates the CDF of non-migrants ('Home') at the 1 percent level of significance. Similarly, the second row indicates that we reject that the CDF of non-migrants dominates the more-unequal-CDF at the 10 percent level. We also reject that the more-equalCDF dominates the less-equal-CDF at the 1 percent level. We even reject these hypotheses when we use the Heckman selection corrected estimates, as reported in Panel A2.

The graphical analysis presented above suggested even more pronounced differences in the CDFs when we limit the comparison to very equal and very unequal countries, respectively. Table 5 (Panel B) indeed shows that the test statistic for the comparison of these more extreme destinations increases substantially. Because the relevant samples become smaller for destinations with more extreme levels of inequality, the $p$-values do not decrease in all cases. Nonetheless, the test of stochastic dominance now rejects at the 5 percent level for all three comparisons. We also test the reverse set of hypotheses and cannot reject these hypotheses. The corresponding $p$-values (which are above 0.95 throughout) are found in Appendix Table A.3.

\subsection{Selection of Migrants by Country}

Our data also allow us to investigate the selection of migrants to each of the 19 destinations in our sample and thereby go beyond the three or five groups of coun-

\footnotetext{
${ }^{28}$ See Appendix A.2 for more details on the bootstrap procedure.
} 


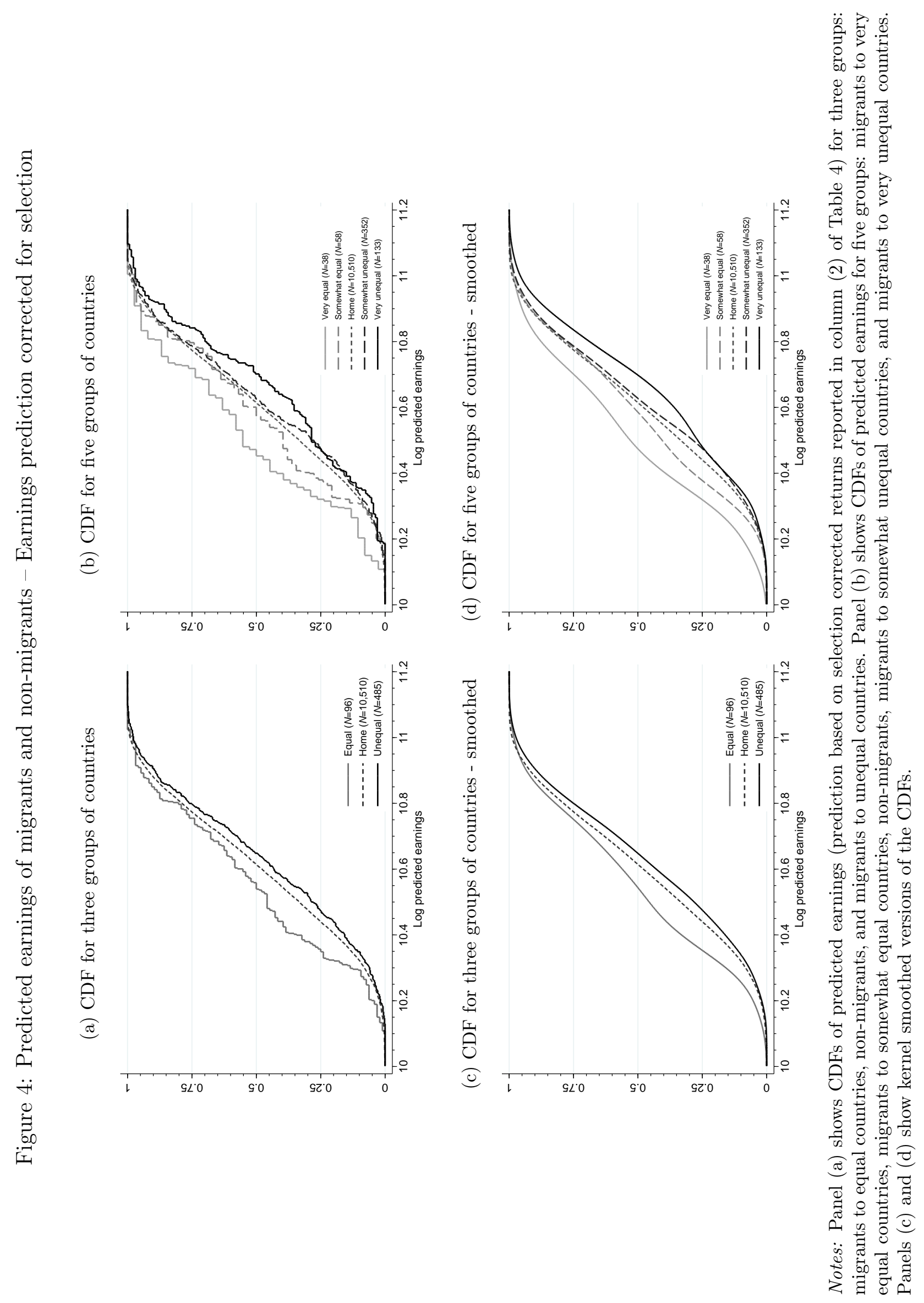


Table 5: Stochastic dominance tests

\begin{tabular}{|c|c|c|c|c|c|}
\hline & \multirow[b]{2}{*}{$\begin{array}{c}\text { Test } \\
\text { statistic }\end{array}$} & \multicolumn{4}{|c|}{$p$-value } \\
\hline & & \multicolumn{2}{|c|}{$\begin{array}{l}\text { Kolmogorov- } \\
\text { Smirnov }\end{array}$} & \multicolumn{2}{|c|}{$\begin{array}{l}\text { Barrett- } \\
\text { Donald }\end{array}$} \\
\hline & (1) & \multicolumn{2}{|c|}{$(2)$} & \multicolumn{2}{|c|}{$(3)$} \\
\hline \multicolumn{6}{|c|}{ Panel A: Selection to more equal and less equal destinations } \\
\hline \multicolumn{6}{|c|}{ Panel A1: OLS } \\
\hline ‘Equal' vs 'Home' & 0.187 & 0.001 & $* * *$ & 0.006 & $* * *$ \\
\hline 'Home' vs 'Unequal' & 0.061 & 0.031 & $* *$ & 0.098 & $*$ \\
\hline 'Equal' vs 'Unequal' & 0.220 & 0.000 & $* * *$ & 0.001 & $* * *$ \\
\hline \multicolumn{6}{|c|}{ Panel A2: Heckman selection correction } \\
\hline 'Equal' vs 'Home' & 0.182 & 0.002 & $* * *$ & 0.022 & $* *$ \\
\hline 'Home' vs 'Unequal' & 0.071 & 0.009 & $* * *$ & 0.083 & $*$ \\
\hline 'Equal' vs 'Unequal' & 0.218 & 0.000 & $* * *$ & 0.004 & $* * *$ \\
\hline
\end{tabular}

\begin{tabular}{lccccc}
\hline \hline \multicolumn{7}{l}{ Panel B: Selection to very equal and very unequal destinations } \\
\hline \multicolumn{7}{c}{ Panel B1: OLS } \\
\hline 'Very equal' vs 'Home' & 0.258 & 0.007 & $* * *$ & 0.018 & $* *$ \\
'Home' vs 'Very unequal' & 0.144 & 0.004 & $* * *$ & 0.017 & $* *$ \\
'Very equal' vs 'Very unequal' & 0.301 & 0.005 & $* * *$ & 0.008 & $* * *$ \\
\hline \multicolumn{7}{c}{ Panel B2: Heckman selection } & correction \\
\hline \multicolumn{7}{c}{ 'Very equal' vs 'Home' } & 0.249 & 0.009 & $* * *$ & 0.041 & $* *$ \\
'Home' vs 'Very unequal' & 0.162 & 0.001 & $* * *$ & 0.014 & $* *$ \\
'Very equal' vs 'Very unequal' & 0.301 & 0.005 & $* * *$ & 0.012 & $* *$ \\
\hline
\end{tabular}

Notes: The table reports one-sided Kolmogorov-Smirnov test statistics and KolmogorovSmirnov and Barrett and Donald $p$-values. Barret and Donald $p$-values are bootstrapped, following equation (11) in Barrett and Donald (2003, p. 82). In the top row ('Equal' versus 'Home'), we test the null hypothesis that the CDF of migrants to more equal destinations stochastically dominates the CDF of non-migrants, and similarly for other rows. The bootstrap is based on 4,999 replications. See text for details. Significance levels: ${ }^{* * *} \mathrm{p}<0.01,{ }^{* *}$ $\mathrm{p}<0.05,{ }^{*} \mathrm{p}<0.1$.

tries presented in the previous section. We compute average predicted earnings of migrants to each country and correlate them with the $75 / 25$ ratio (Figure 5 ). Circle sizes indicate the number of migrants in each country. Apart from a few outliers, migrants to more equal countries have lower predicted earnings than migrants to less equal countries.

We estimate a weighted country-level OLS regression and show the corresponding prediction in Figure 5. In particular, we regress average predicted earnings $\left(\overline{\hat{\theta}}_{0 c}\right)$ on the $75 / 25$ ratio in each country $c$ :

$$
\overline{\hat{\theta}}_{0 c}=\gamma_{0}+\gamma_{1} 75 / 25 \text { ratio }_{c}+\varepsilon_{c}
$$


Figure 5: Predicted earnings and inequality across destinations

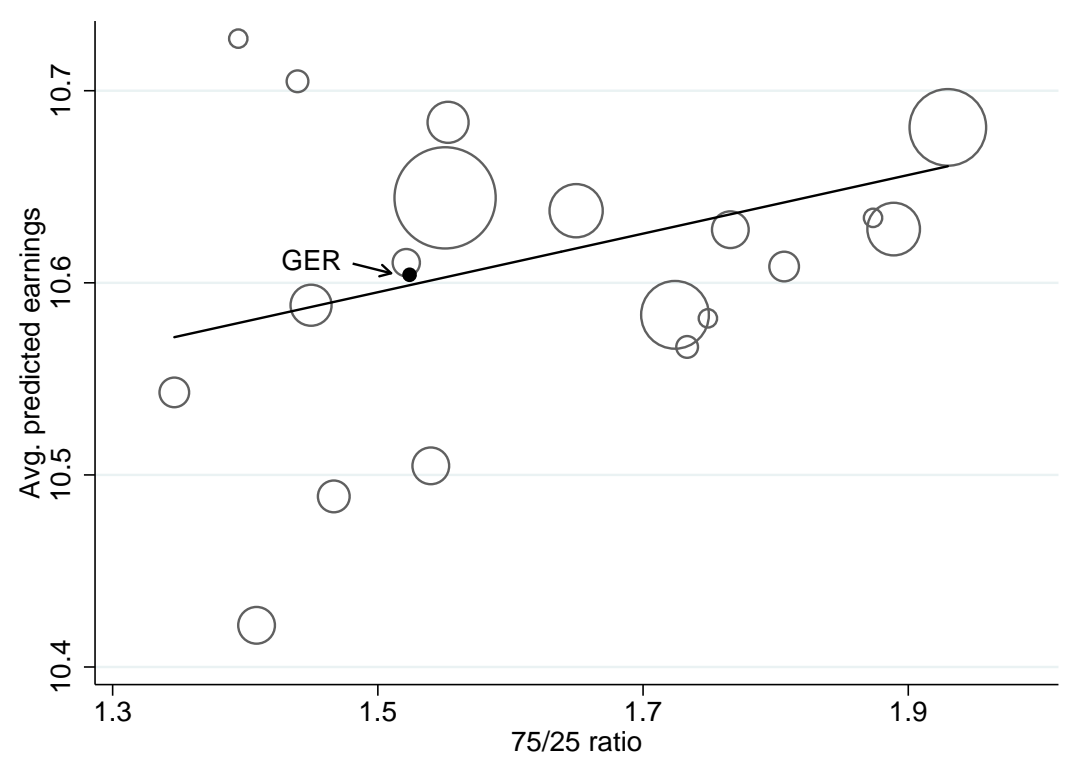

Notes: The figure shows average predicted earnings for migrants to each country and the corresponding $75 / 25$ inequality ratio. Circle sizes are proportional to the number of migrants in each destination. The regression line reported in the figure is estimated through a weighted regression with weights equal to the number of migrants in each country.

The estimated regression line $\left(\hat{\gamma}_{1}\right)$ has a slope of 0.153 with a standard error of 0.081 (Table 6 , column 1, significant at the 10 percent level). ${ }^{29}$ This estimate indicates that migrants to destinations with a $75 / 25$ ratio that is higher by 0.4 (the difference between Germany and the United States) have predicted earnings that are $6.1 \log$ points higher.

\section{Robustness}

\subsection{Controlling for Possible Confounding Factors}

The selection pattern described in the previous section is consistent with the theoretical predictions of the Roy/Borjas model. Earnings inequality, however, is not the only factor that differs between home and destination countries. Countries may also differ along other dimensions that could be correlated with migrant selection.

We first analyze whether confounding factors $\left(F_{c}\right)$ are driving our selection re-

\footnotetext{
${ }^{29}$ An unweighted regression has a slope equal to 0.103 with a standard error of 0.101 .
} 
sults by controlling for them in the cross-country regression (see Table 6): ${ }^{30}$

$$
\overline{\hat{\theta}}_{0 c}=\gamma_{0}+\gamma_{1} 75 / 25 \text { ratio }_{c}+\gamma_{2} F_{c}+\varepsilon_{c}
$$

The Roy/Borjas model predicts that mean earnings should affect the number of migrants to each country but not the direction of selection. Nonetheless, differences in mean earnings will affect migration choices and may be correlated with differences in the $75 / 25$ ratios. In our first robustness check, we therefore control for average log earnings in each country. In this specification, the coefficient on the $75 / 25$ ratio increases slightly to 0.180 , suggesting an even stronger relationship between inequality and migrant selection (column (2), significant at the 1 percent level). Migration decisions, especially those of lower-skilled migrants (among the high-skilled), may also be affected by expected unemployment spells that could be correlated with earnings inequality. We therefore control for unemployment rates of tertiary-educated people in each country. In this specification, the coefficient on the $75 / 25$ ratio is equal to 0.174 (Table 6, column 3, significant at the 5 percent level). Migration decisions, especially of high-skilled women, may also be affected by differences in child care provision that may be correlated with earnings inequality. To address this concern, we control for public expenditures on family benefits. In this specification, the coefficient on the $75 / 25$ ratio is equal to 0.110 and remains significant at the 10 percent level (Table 6, column 4). As migration decisions may also be affected by expectations about general well-being that may be correlated with earnings inequality, we control for a measure of life satisfaction in each country. In this specification, the coefficient on the $75 / 25$ ratio is 0.247 confirming a strong relationship between earnings inequality and migrant selection (Table 6 , column 5 , significant at the 1 percent level). Lastly, we control for all potential confounders at the same time. In this specification, the coefficient on the $75 / 25$ ratio is 0.147 , with a $p$-value of 0.061 . These results indicate a stable relationship between earnings inequality and migrant selection (Table 6, column 6).

The previous checks confirm a robust effect of earnings inequality on mean selection levels. In additional tests, we investigate how potential confounders affect selection across the whole distribution of skills. For these tests, we first replicate the CDFs from our main results using quantile regressions, and then control for possible confounding factors using the quantile regression framework. We regress predicted earnings of each individual $i\left(\hat{\theta}_{0 i}\right)$ on country group dummies separately

\footnotetext{
${ }^{30}$ Data on mean earnings are constructed from the same sources as the $75 / 25$ ratios. Data on the other control variables come from the OECD. See Appendix section B.2 for details.
} 
Table 6: Cross-country regressions

\begin{tabular}{lcccccc}
\hline & $(1)$ & $(2)$ & $(3)$ & $(4)$ & $(5)$ & $(6)$ \\
\hline $75 / 25$ ratio & $0.153^{*}$ & $0.180^{* * *}$ & $0.174^{* *}$ & $0.110^{*}$ & $0.247^{* * *}$ & $0.147^{*}$ \\
& $(0.081)$ & $(0.058)$ & $(0.077)$ & $(0.057)$ & $(0.081)$ & $(0.071)$ \\
Mean earnings & & $0.110^{* * *}$ & & & & $0.102^{*}$ \\
& & $(0.033)$ & & & & $(0.056))$ \\
Tertiary-educated unemployment share & & & -0.007 & & & 0.005 \\
& & & $(0.007)$ & & & $(0.009)$ \\
Family expenditure & & & & $-0.023^{*}$ & & -0.012 \\
& & & & $(0.011)$ & & $(0.011)$ \\
Life satisfaction & & & & & $0.050^{*}$ & 0.003 \\
& $10.366^{* * *}$ & $9.161^{* * *}$ & $10.353^{* * *}$ & $10.484^{* * *}$ & $9.849^{* * *}$ & $9.281^{* * *}$ \\
Constant & $(0.144)$ & $(0.413)$ & $(0.138)$ & $(0.104)$ & $(0.276)$ & $(0.531)$ \\
\hline R-sq. & 0.183 & 0.475 & 0.204 & 0.317 & 0.282 & 0.514 \\
Observations & 19 & 19 & 19 & 19 & 19 & 19 \\
\hline
\end{tabular}

Notes: The table reports weighted regressions of average predicted earnings of migrants in each country on the corresponding $75 / 25$ ratio and potential confounders. Significance levels: ${ }^{* * *} \mathrm{p}<0.01,{ }^{* *} \mathrm{p}<0.05,{ }^{*} \mathrm{p}<0.1$.

for 100 centiles $(\tau=0.01 \ldots 0.99)$ of the predicted earnings distribution:

$$
\begin{aligned}
\hat{\theta}_{0 i c}= & \delta_{0 \tau}+\delta_{1 \tau} \text { Very Equal }_{i c}+\delta_{2 \tau} \text { Somewhat Equal }_{i c}+ \\
& \delta_{3 \tau} \text { Somewhat Unequal }_{i c}+\delta_{4 \tau} \text { Very Unequal }_{i c}+\epsilon_{i c \tau}
\end{aligned}
$$

Very Equal ${ }_{i c}$ takes a value of 1 if the individual works in a country that is much more

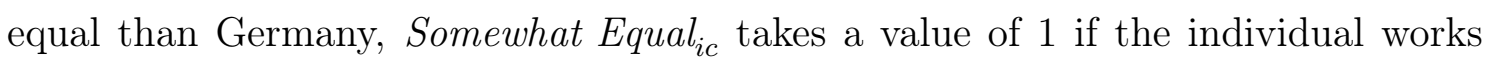
in a country that is somewhat more equal, and so on. ${ }^{31}$ The constant represents predicted earnings for individuals who work in Germany. Figure 6(a) shows the quantile regression equivalents of the CDFs in our main results. We then control for potential confounding factors in the quantile regressions by adding country-level controls:

$$
\begin{aligned}
\hat{\theta}_{0 i c}= & \delta_{0 \tau}+\delta_{1 \tau} \text { Very Equal }_{i c}+\delta_{2 \tau} \text { Somewhat Equal }_{i c}+ \\
& \delta_{3 \tau} \text { Somewhat Unequal }_{i c}+\delta_{4 \tau} \text { Very Unequal }_{i c}+\delta_{5 \tau} F_{c}+\epsilon_{i c \tau}
\end{aligned}
$$

From the estimated coefficients, we then reconstruct CDFs for each group. To ensure comparability with our results, we fix the value of the added covariate at the German level. ${ }^{32}$ Panels (b) to (f) of Figure 6 show CDFs that are adjusted for the same confounding factors that we have analyzed in the cross-country regression (see

\footnotetext{
${ }^{31}$ Categories are defined as for our main results. The results reported below use predicted earnings $\left(\hat{\theta}_{0 i c}\right)$. These were estimated in models that control for selection in the Mincer regression using ERASMUS as an instrument for working in Germany. Results that are based on predicted earnings from the uncorrected Mincer regression are very similar.

${ }^{32}$ The derived CDFs from the quantile regressions occasionally violate local monotonicity. We therefore apply the rearrangement method from Chernozhukov et al. (2010). While this procedure ensures monotonicity in the CDFs, the estimates without this procedure are very similar.
} 
Table 6). The selection pattern to locations with more extreme levels of equality or inequality is robust to controlling for country-level confounding factors. The selection pattern to locations with more similar levels of (in)equality remains broadly consistent with the predictions of the model. The most important deviation from the model prediction occurs for selection to somewhat unequal countries, in particular if we control for mean earnings.

\subsection{Sensitivity Analysis to Alternative Inequality Measures}

In this section, we investigate the sensitivity of our main results to using alternative measures of inequality. The results are shown in Appendix Figure A.2. They focus on the three-group comparison with correction for sample selection in the Mincer regression. Panel (a) provides the main results, which are based on the 75 th to 25 th graduate earnings ratio. Panels (b) to (d) use different measures to compare earnings inequality in Germany to inequality in other countries. First, we measure inequality with the $75 / 25$ ratio of the whole population. This alternative measure is probably less relevant for the migration decisions of university graduates but has the advantage that inequality is measured in larger samples. ${ }^{33}$ The resulting CDFs are very similar (panel (b)); if anything, the differences across the three groups are slightly more pronounced when we use this broader measure to classify countries. Because graduates are concentrated in the upper percentiles of the overall distribution, we investigate the sensitivity of our results when we classify countries according to the 90/50 ratio of the overall population. Again, the results are essentially unchanged (panel (c)). Finally, we show results where we classify countries according to the Gini coefficient reported by the OECD, and thus from a completely different data source, for the overall population. The nature of selection across the three groups remains unchanged (panel (d)), even though the difference between the CDFs of migrants to more equal destinations and non-migrants is now reduced.

\subsection{Selection to Europe and to Austria/Switzerland}

Additionally, we investigate selection to European countries only. German citizens who migrate to these countries face virtually no migration barriers, such as visa requirements. Germans can settle freely in any country of the European Union

\footnotetext{
${ }^{33}$ When we restrict the country level earnings surveys to university graduates, the samples in some countries become relatively small (see Appendix Table A.1). Inequality measures for university graduates that are based on more extreme percentiles than the 75 th or the 25 th percentiles are therefore more likely to be affected by outliers.
} 
Figure 6: CDFs adjusted for potential confounders

(a) Baseline

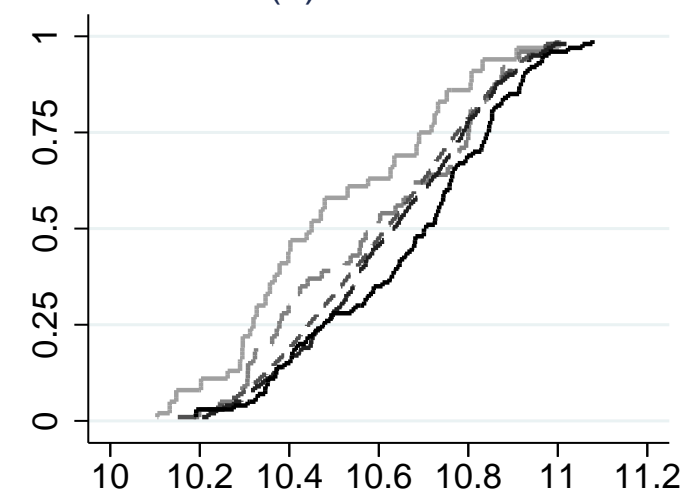

(c) Family expenditure

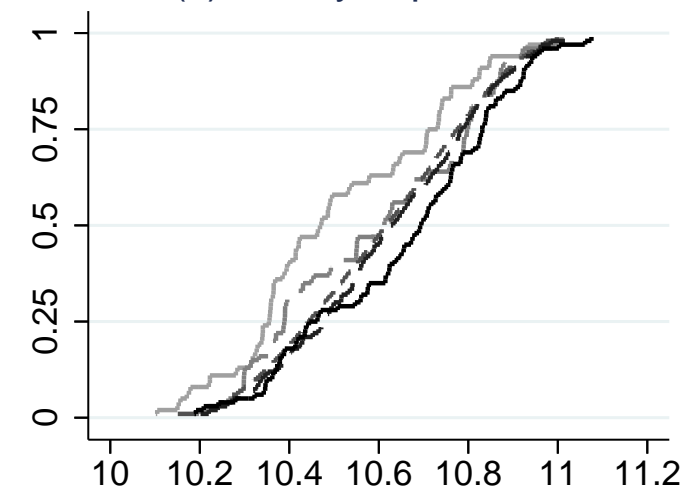

(e) Life satisfaction

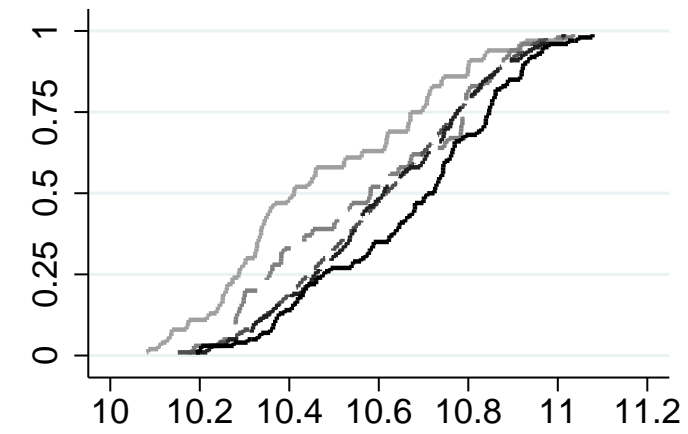

Log predicted earnings (b) Log net earnings

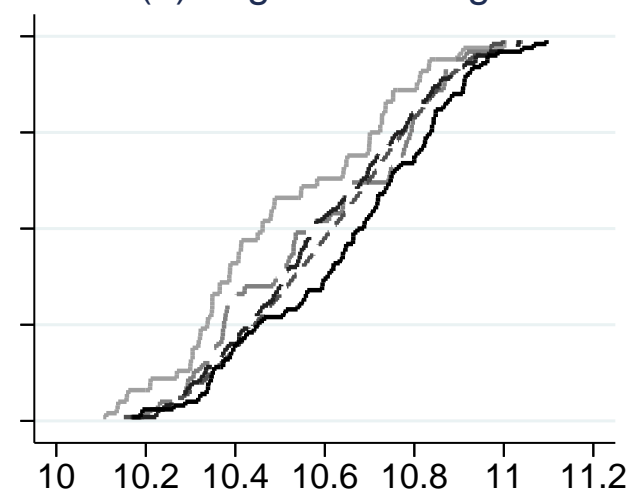

(d) Unemployment rate

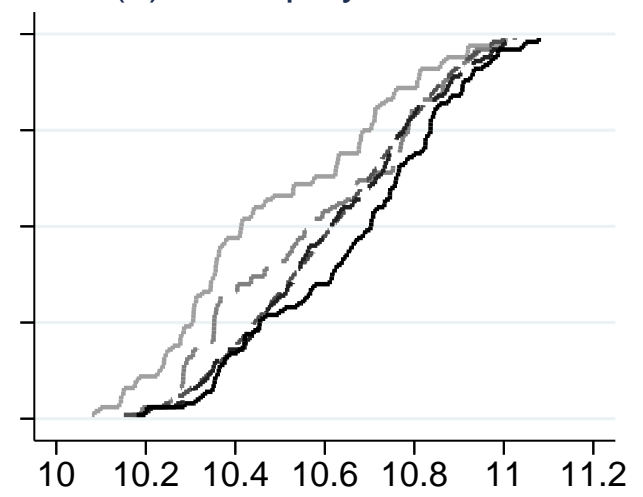

(f) All controls

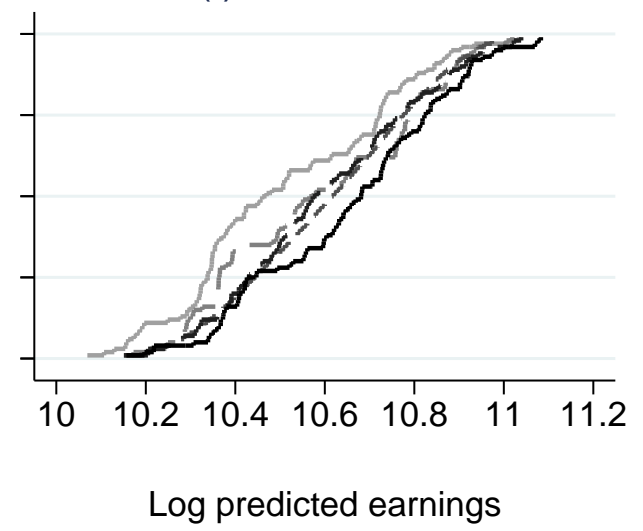

Notes: The figure shows adjusted CDFs of predicted earnings based on quantile regressions. Panel (a) replicates the baseline CDFs from Figure 4 (b). In panel (b), we control for log net earnings, in panel (c) for public expenditures on family benefits as percentage of GDP, in panel (d) for the tertiary-educated unemployment rate, in panel (e) for life satisfaction, and in panel (f) for all controls. 
Figure 7: Predicted earnings of migrants to Europe and Austria/Switzerland

(a) Europe

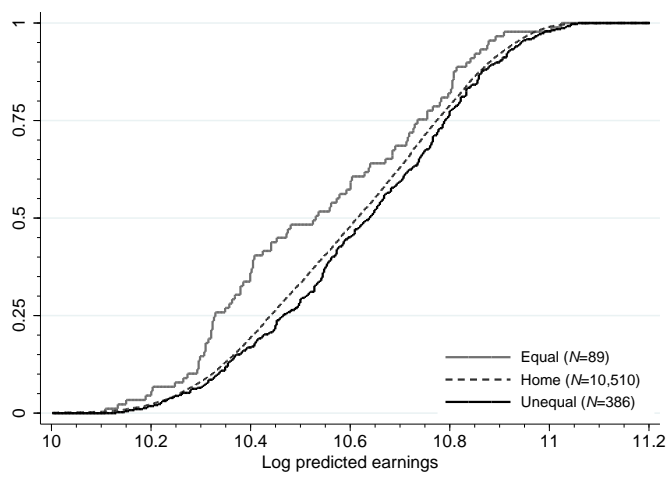

(b) Austria and Switzerland

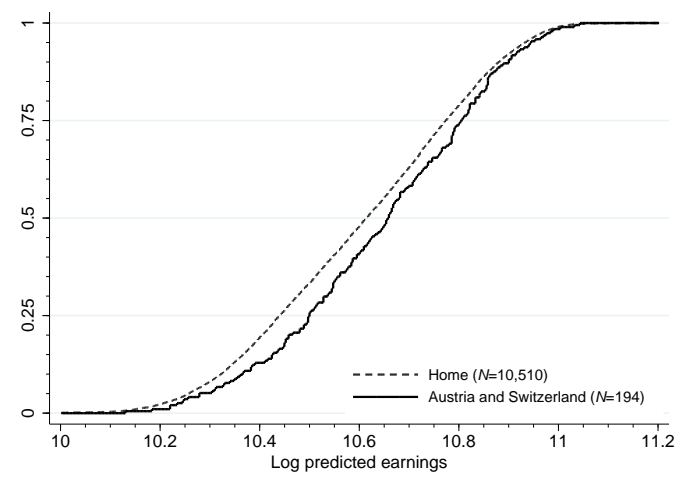

Notes: The figure shows CDFs of predicted earnings (prediction based on selection corrected returns reported in column (2) of Table 4) for migrants to Austria or Switzerland and non-migrants.

and in other European countries, such as Switzerland, Lichtenstein, and Norway. ${ }^{34}$ Furthermore, migration costs to these countries are relatively low because distances within Europe are small, and travel costs are low.

We plot CDFs of predicted earnings of migrants to less equal countries, migrants to more equal countries, and non-migrants (Figure 7(a)). As for the full sample, migrants to more equal European countries are negatively selected and migrants to less equal European destinations are positively selected, compared to non-migrants. ${ }^{35}$ These results suggest that differential migration costs are not driving our main results.

In an additional test, we investigate migrant selection to Austria and Switzerland only. These two countries are very similar to Germany along many dimensions that may affect migration choices. The countries have similar education systems; in the three countries, between 31 and 35 percent of each cohort graduated from university in 2011 (OECD 2013b, p. 61). ${ }^{36}$ The countries also have comparable labor market institutions; unemployment benefits measured by replacement rates ranged between 29 and 33 percent of gross incomes in 2005 (OECD, 2015). Finally,

\footnotetext{
${ }^{34}$ Graduates from the earlier cohorts in our sample may have had some (minor) restrictions to settle in a small subset of these countries. This only affects graduates from the 1993 to 2001 cohorts who migrated to Poland or Switzerland.

${ }^{35}$ We test whether the differences between the CDFs remain significant. We reject that the CDF of migrants to more equal countries dominates the home CDF at the 5 percent level (Appendix Table A.4, Panel A2). As the European sample contains few very unequal countries, we no longer reject that the home $\mathrm{CDF}$ dominates the CDF of migrants to less equal countries (the p-value of this test is 0.19 ).

${ }^{36}$ These numbers are higher than the 11 percent reported above because they refer to students from younger cohorts and include students at universities of applied sciences.
} 
the three countries also share a similar culture and language. ${ }^{37}$ While the three countries are similar along many dimensions, they differ in earnings inequality of university graduates. Both Austria and Switzerland are less equal than Germany. The CDF of predicted earnings of migrants to Austria and Switzerland lies to the right of the non-migrant CDF (Figure 7(b)). ${ }^{38}$ These results indicate that migrants to Austria and Switzerland are positively selected compared to non-migrants, as predicted by the Roy/Borjas model.

\section{$5 \quad$ Further Results}

\subsection{Decomposing Migrant Selection}

Predicted earnings can be considered a summary measure of different skills. In the following, we decompose the estimated difference in predicted earnings between migrants and non-migrants to understand the characteristics that drive the observed selection patterns. We use the estimated coefficients from our selection-corrected Mincer regression (Table 4, column (2)) and multiply them by the average characteristics in each group (non-migrants, migrants to less equal countries, migrants to more equal countries). Results are shown in Figure 8.

The positive selection of migrants to less equal countries is mostly driven by their university career (panel (a)). They have better grades and attend better universities than non-migrants. The negative selection of migrants to more equal countries is driven by their university subject, university quality, and gender (panel (b)). They study subjects with lower returns in the labor market, enroll at universities with less favorable labor market prospects, and are more often female. Interestingly, migrants to less equal countries have better grades at university, despite being negatively selected overall. This is consistent with findings that suggest that migrants are positively selected when skill is measured in terms of education.

The decomposition indicates that migrant selection is not uniform across different characteristics. Such differences in selection patterns across groups of characteristics could at least partially explain the different findings in the literature. Earnings are a natural way to summarize overall selection patterns, which can be decomposed to understand selection according to different characteristics.

\footnotetext{
${ }^{37}$ The whole of Austria is German-speaking and in Switzerland, around 64 percent of the population speaks German. In 2010, more than 90 percent of German migrants to Switzerland lived in predominantly German speaking regions (Kantons) (own calculations based on BFS, 2010, 2013).

${ }^{38}$ The test that the home CDF dominates the Austria/Switzerland CDF is rejected at the 10 percent level (Appendix Table A.4, Panel C).
} 
Figure 8: Decomposition of predicted earnings

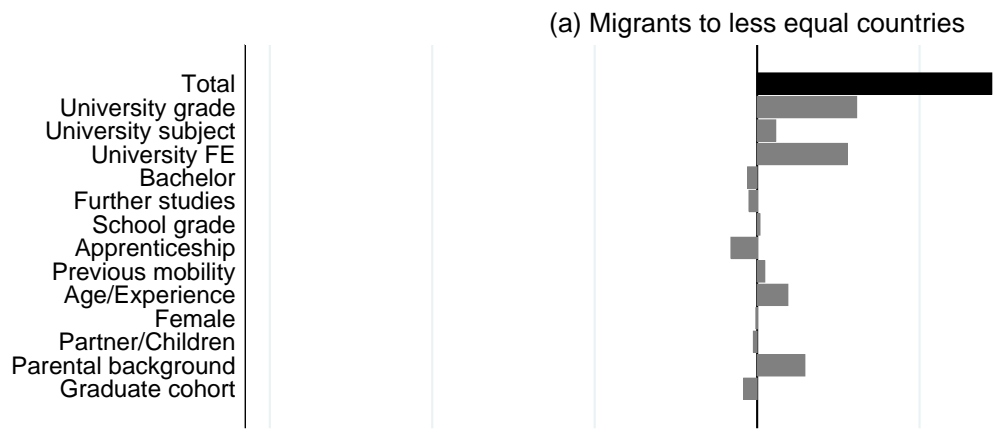

(b) Migrants to more equal countries

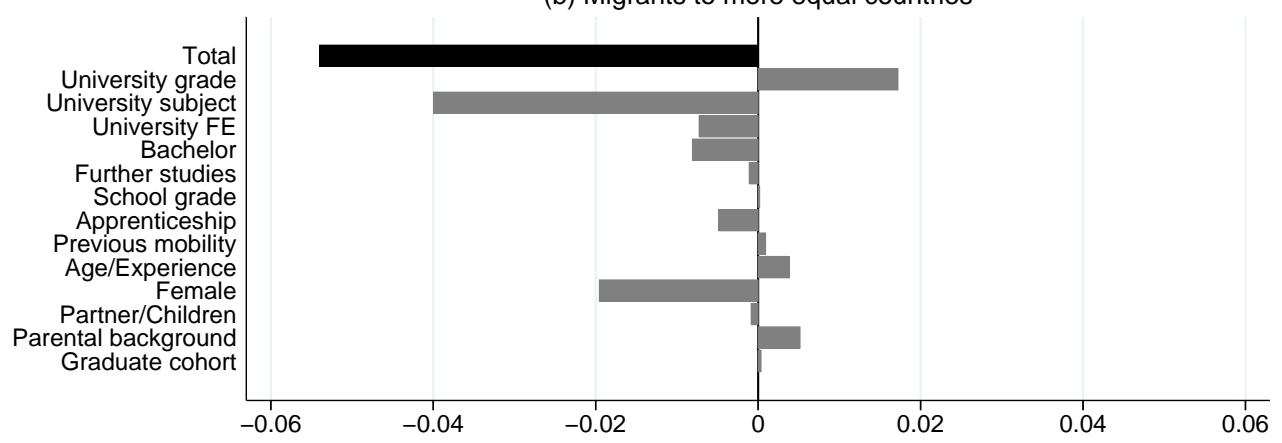

Notes: Panel (a) decomposes the mean difference in predicted earnings between migrants to less euqal countries and non-migrants. The top bar (black) measures the total difference in predicted earnings. The other bars decompose the total difference into the contributions of groups of characteristics (e.g. university grade). The size of the bars is obtained by multiplying estimated returns ( $\hat{\beta}$ from column (2) in Table 4 ) with average charactistics, $\bar{x}$, of migrants to less equal countries

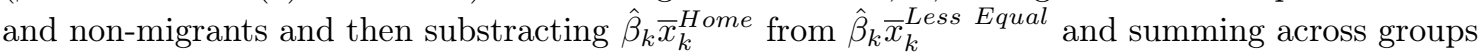
of charakteristics $k$ as shown in the figure. Panel (b) presents the equivalent decomposition of the mean differences in predicted earnings between migrants to more equal destinations and nonmigrants.

\subsection{Migration to the United States}

\section{Migrants to the United States Compared to German Stayers}

In the final section, we investigate migrant selection to the United States. The United States is an important destination for German university graduates. In our sample, more than 13 percent of graduates who go abroad move to the United States; only Switzerland attracts more graduates from Germany. Because U.S. inequality is highest among the major destinations of German university graduates, we expect that German university graduates who migrate to the United States are particularly positively selected.

We plot the CDF of predicted earnings of migrants to the United States and compare them to the CDF of non-migrants (Figure 9(a)). The CDF of migrants to 
Figure 9: Predicted earnings of migrants to the United States

(a) $\mathrm{CDF}$

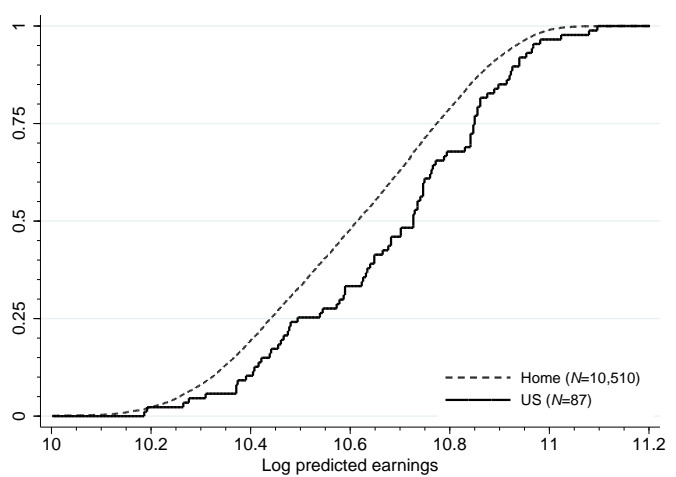

(b) Decomposition

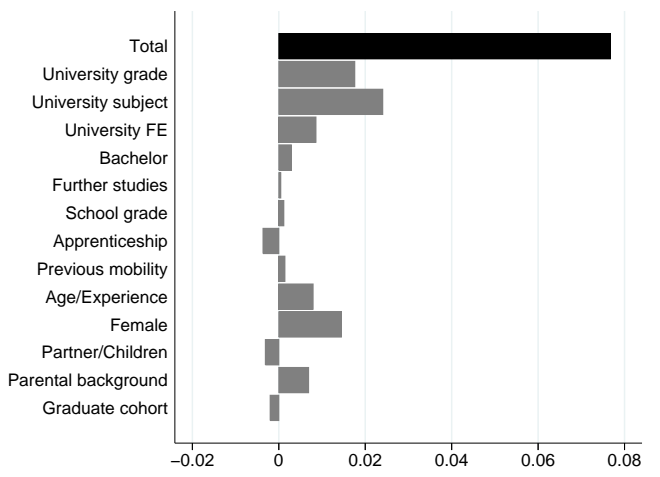

Notes: Panel (a): The figure shows CDFs of predicted earnings (prediction based on selection corrected returns reported in column (2) of Table 4) for migrants to the United States and nonmigrants. Panel (b): The figure decomposes the mean difference in predicted earnings between migrants to the United States and non-migrants. The top bar (black) measures the total difference in predicted earnings. The other bars decompose the total difference into the contributions of groups of characteristics (e.g. university grade). See Figure 8 for further details.

the United States always lies to the right of the non-migrant CDF. The difference between the CDFs of U.S. migrants and non-migrants is more pronounced than the difference between the CDFs of all migrants to less equal countries and non-migrants. This highlights the particularly positive selection of migrants to the United States. A test of the stochastic dominance of the non-migrant-CDF over the U.S.-CDF is rejected at the 5 percent level (see Appendix Table A.4).

To get a better understanding of the characteristics that drive migrant selection to the United States, we decompose the difference in predicted earnings between migrants to the United States and non-migrants. Migrants to the United States have predicted earnings that are about 8 log points higher than non-migrants (Figure 9(b)). U.S. migrants are positively selected according to almost all characteristics. The most important drivers of migrant selection to the United States are characteristics that relate to the university career and gender. Migrants to the United States study subjects with especially high returns (see third bar from the top in Figure 9(b)). In fact, they are particularly concentrated in STEM fields. In our sample, about 17.2 percent of migrants to the United States hold a degree in physics (but only 3.9 percent of non-migrants). Similarly, 9.2 percent of U.S. migrants have a biology degree (non-migrants 2.3 percent) and 8.1 percent of U.S. migrants have a chemistry degree (non-migrants 3.0 percent). ${ }^{39}$ Compared to non-migrants, migrants to the United States are also more likely to hold degrees in computer science,

\footnotetext{
${ }^{39}$ The differences between U.S. migrants and non-migrants are significant at the 1 percent level.
} 
economics and management, geography, and engineering and they are less likely to hold degrees in law, languages, medicine, architecture, and education. ${ }^{40}$ Furthermore, migrants to the United States obtain much higher grades in university than non-migrants (1.6 versus 2.0 in a system where 1.0 is the highest grade and 4.0 the lowest passing grade). They also study in universities where graduates have higher predicted earnings.

The decomposition indicates that the United States attracts high-skilled migrants from Germany who have studied in better universities, received higher grades, and are concentrated in high-paying STEM fields. Thus, migrants to the United States are precisely the migrants that are considered to be important for innovation and technological progress.

\section{Migrants from Germany Compared to U.S. Natives in the ACS}

Finally, we investigate how high-skilled migrants from Germany fare in the U.S. labor market by comparing earnings potential of high-skilled migrants from Germany to high-skilled natives in the United States. For this test, we use data from the American Community Survey (ACS) and identify high-skilled migrants from Germany as individuals who were born in Germany, who migrated to the United States after age 25, who do not have U.S. parents, and who migrated to the United States between 1996 and 2010. These restrictions ensure that our sample of Germans in the United States is as similar as possible to the sample of graduates who are the subject of our study. To focus our analysis on the high-skilled, we limit the sample to individuals with a bachelor's degree or higher, who worked for 50 to 52 weeks per year in full-time jobs and are 30 to 45 years old (see Data Appendix B.3 for further details on the ACS data).

We then compare predicted earnings of migrants from Germany to earnings of U.S. natives. In terms of the Roy/Borjas model, this test compares the distribution of $\hat{\theta}_{1}$ of German migrants in the United States to U.S. natives, while our previous results compared distributions of $\hat{\theta}_{0}$ of migrants and non-migrants. ${ }^{41}$ Indeed, our results show that compared to high-skilled U.S. natives, recent migrants from Germany have far higher predicted earnings in the U.S. labor market. The CDF of

\footnotetext{
${ }^{40}$ The differences between these additional specializations of migrants to the United States and non-migrants are only significant (at the 5 percent level) for geography, law, and languages.

${ }^{41}$ Parallel to equation (5), the corresponding equation for selection in terms of earnings potential in the destination country is
}

$$
E\left(\theta_{1} \mid \text { Migrate }=1\right)=\mu_{1}+\left(\frac{\sigma_{\theta_{1}}}{\sigma_{\theta_{0}}}-\rho_{\theta}\right) \frac{\sigma_{\theta_{0}} \sigma_{\theta_{1}}}{\sigma_{v}} \frac{\phi(z)}{1-\Phi(z)} .
$$


Figure 10: Predicted earnings of migrants to the United States in the United States

(a) $\mathrm{CDF}$

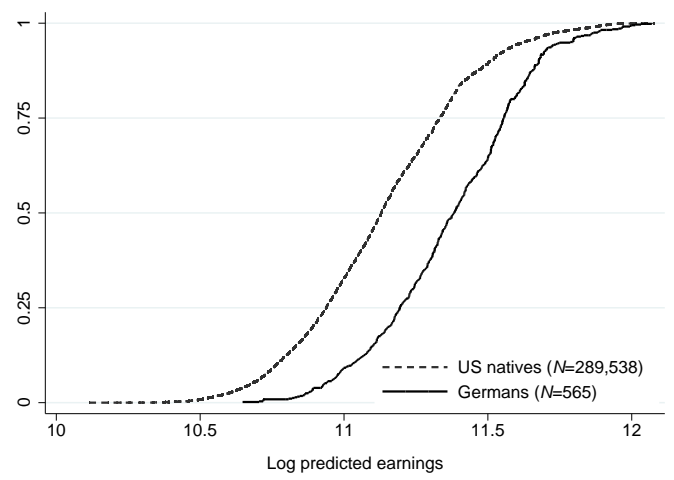

(b) Decomposition

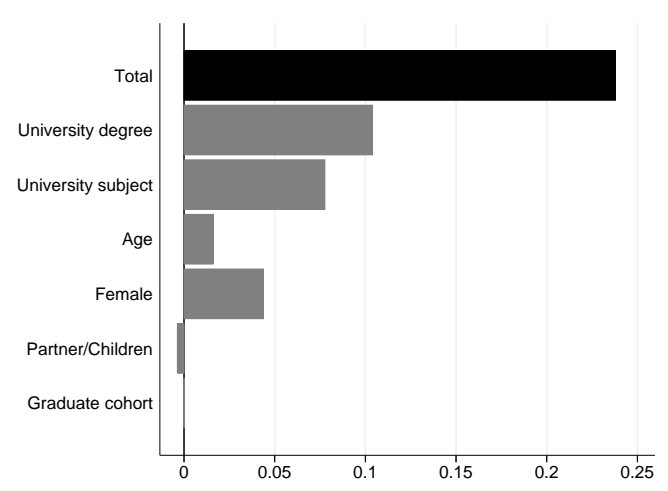

Notes: Panel (a): The figure shows CDFs of predicted earnings in the United States. Prediction based on coefficients of the Mincer regression reported in Appendix Table A.5 using ACS data on U.S. natives. Panel (b): The figure decomposes the mean difference in predicted earnings between German migrants to the United States and U.S. natives. The top bar (black) measures the total difference in predicted earnings. The other bars decompose the total difference into the contributions of groups of characteristics (e.g. university degree).

predicted earnings of German immigrants lies to the right of the native CDF along the whole earnings distribution (Figure 10(a)). At the median, log predicted earnings of migrants from Germany are 11.462, while log earnings of natives are 11.083. At the 25th and 75th percentiles, migrants from Germany have predicted earnings of 11.0184 and 11.866, while natives have predicted earnings of 10.731 and 11.493 . (Figure 10(b)). A back-of-the-envelope calculation suggests that the stronger degree selection in terms of $\theta_{1}$ (relative to our earlier results in terms of $\theta_{0}$ ) can be reconciled with our theoretical prediction, both qualitatively and quantitatively. ${ }^{42}$

Overall, these results indicate that high-skilled individuals who migrate from Germany to the United States are not only positively selected compared to Germans who do not migrate, but also compared to non-migrants in the United States. To investigate the contribution of different characteristics, we also decompose the difference in predicted earnings between German migrants to the United States and U.S. natives. Because the ACS data are less detailed than our graduate survey data, the decomposition involves fewer characteristics. Compared to U.S. natives, Ger-

\footnotetext{
${ }^{42}$ The selection in terms of $\theta_{1}$ should be stronger than selection in terms of $\theta_{0}$ by a factor of $\left(\frac{\sigma_{\theta_{1}}}{\sigma_{\theta_{0}}}-\rho_{\theta}\right) /\left(\rho_{\theta}-\frac{\sigma_{\theta_{0}}}{\sigma_{\theta_{1}}}\right)$. Between the United States and Germany, the ratio $\frac{\sigma_{\theta_{0}}}{\sigma_{\theta_{1}}}$ is about 0.8 in our data. While parameter $\rho_{\theta}$ is not known, the positive selection in terms of $\theta_{0}$ indicates that $\rho_{\theta}$ is larger than 0.8 (from equation (5)). Suppose hypothetically that $\rho_{\theta}$ takes a value of 0.9 , then the factor results in a value of 3.7 , which is broadly similar but slightly larger than the observed difference in selection. Because the factor decreases in $\rho_{\theta}$, it is straightforward to reconcile the observed difference in selection with a value of $\rho_{\theta}$ somewhat larger than 0.9.
} 
man migrants have more advanced degrees (such as professional degrees or PhDs) and graduated with degrees in subjects (in particular STEM subjects) that typically lead to higher-paid employment. German migrants are also less likely to be female than U.S. natives. Overall, the positive selection compared to U.S. natives is driven by similar characteristics that also drive the positive selection compared to German non-migrants.

\section{Conclusion}

The seminal work of Borjas has emphasized how migrant selection is driven by inequality in home and destination countries: high-skilled individuals benefit from the upside opportunities in less equal countries, and low-skilled individuals benefit from the insurance of a more compressed wage distribution in more equal countries. This insight has motivated various empirical tests of the Borjas model. In spite of the large differences in inequality across many home-destination country pairs, the empirical evidence is mixed. To help reconcile the model with the observed patterns of selection, researchers have subsequently studied modifications to the original model, such as accounting for moving costs that vary with skills (Chiquiar and Hanson, 2005).

In this paper, we investigate selection within the group of high-skilled migrants. Studying high-skilled migrants is particularly relevant because high-skilled talent is key for firms' success in internationally competitive environments. Compared to low-skilled migrants, high-skilled individuals face lower costs and fewer formal restrictions to migration. These features suggest that the economic forces described by the Roy/Borjas model should be particularly relevant for high-skilled individuals.

We study migrant selection among university graduates using predicted wages to measure skills. We find that migrants to more equal countries, such as Denmark, are negatively selected compared to non-migrants. Migrants to less equal countries, such as the United States, are positively selected. The observed selection patterns are consistent with the predictions of the basic Roy/Borjas model.

We show that migrant selection follows the predictions of the basic Roy/Borjas model even within subgroups of either more or less equal countries. Furthermore, our results are robust to controlling for potentially confounding factors and to using alternative measures of inequality in destination countries. We also demonstrate that the selection pattern holds when we study migration within Europe, and migration to Austria and Switzerland only, where barriers to migration are almost absent. When we decompose predicted earnings into various skill components, we find that 
selection is not uniform across all characteristics. Negative selection to more equal countries is mostly driven by gender, university subject, and university quality. Positive selection to less equal countries is mostly driven by university grades and university quality. Finally, we show that migrants to the United States are not only positively selected compared to German non-migrants but also compared to U.S. native graduates.

Our findings highlight the importance of the Roy/Borjas model for the selection of high-skilled migrants.

\section{References}

Abramitzky, R., Boustan, L. P., and Eriksson, K. (2012). Europe's Tired, Poor, Huddled Masses: Self-Selection and Economic Outcomes in the Age of Mass Migration. American Economic Review, 102(5):1832-1856.

Akcigit, U., Baslandze, S., and Stantcheva, S. (2015). Taxation and the International Mobility of Inventors. NBER Working Paper No. 21024.

Barrett, G. F. and Donald, S. G. (2003). Consistent Tests for Stochastic Dominance. Econometrica, 71(1):71-104.

Bartolucci, C., Villosio, C., and Wagner, M. (2014). Who Migrates and Why? Evidence from Italian Administrative Data. Working Paper.

Belot, M. V. K. and Hatton, T. J. (2012). Immigrant Selection in the OECD. Scandinavian Journal of Economics, 114(4):1105-1128.

BFS (2010). Ständige und Nichtständige Wohnbevölkerung nach Kanton, Geschlecht, Anwesenheitsbewilligung, Altersklasse und Staatsangehörigkeit. Report. BFS (2013). Ständige Wohnbevölkerung nach Kanton und Hauptsprachen. Report.

Borjas, G. J. (1987). Self-Selection and the Earnings of Immigrants. American Economic Review, 77(4):531-553.

Borjas, G. J. (2008). Labor Outflows and Labor Inflows in Puerto Rico. Journal of Human Capital, 2(1):32-68.

Borjas, G. J., Bronars, S. G., and Trejo, S. J. (1992). Self-Selection and Internal Migration in the United States. Journal of Urban Economics, 32(2):159-185.

Borjas, G. J. and Doran, K. B. (2012). The Collapse of the Soviet Union and the Productivity of American Mathematicians. Quarterly Journal of Economics, 127(3):1143-1203.

Borjas, George, J. (2014). Immigration Economics. Harvard University Press. 
Brücker, H., Bertoli, S., Facchini, G., Mayda, A. M., and Peri, G. (2012). Understanding Highly Skilled Migration in Developed Countries: The Upcoming Battle for Brains. In Boeri, T., Brücker, H., Docquier, F., and Rapoport, H., editors, Brain Drain and Brain Gain - The Global Competition to Attract High-Skilled Migrants, pages 15-188. Oxford University Press.

Card, D. (1999). The Causal Effect of Education on Earnings. In Ashenfelter, O. C. and Card, D., editors, Handbook of Labor Economics, volume 3A, chapter 30, pages 1801-1863. Elsevier, North-Holland.

Card, D., Heining, J., and Kline, P. (2013). Workplace Heterogeneity and the Rise of West German Wage Inequality. Quarterly Journal of Economics, 128(3):9671015.

Chambers, E. G., Foulon, M., Handfield-Jones, H., Hankin, S. M., and Michaels, E. G. (1998). The War for Talent. McKinsey Quarterly, 3:44-57.

Chernozhukov, V., Fernández-Val, I., and Galichon, A. (2010). Quantile and Probability Curves without Crossing. Econometrica, 78(3):1093-1125.

Chiquiar, D. and Hanson, G. H. (2005). International Migration, Self-Selection, and the Distribution of Wages: Evidence from Mexico and the United States. Journal of Political Economy, 113(2):239-281.

DESTATIS (2013). Bildungsstand der Bevölkerung. Federal Statistical Office, Germany.

Docquier, F. and Rapoport, H. (2012). Globalization, Brain Drain, and Development. Journal of Economic Literature, 50(3):681-730.

Doran, K., Gelber, A., and Isen, A. (2014). The Effects of High-Skilled Immigration on Firms: Evidence from H-1B Visa Lotteries. NBER Working Paper No. 20668.

Dustmann, C., Fadlon, I., and Weiss, Y. (2011). Return Migration, Human Capital Accumulation and the Brain Drain. Journal of Development Economics, 95(1):5867.

Dustmann, C., Ludsteck, J., and Schönberg, U. (2009). Revisiting the German Wage Structure. Quarterly Journal of Economics, 124(2):843-881.

Feliciano, C. (2005). Educational Selectivity in U.S. Immigration: How Do Immigrants Compare to Those Left Behind? Demography, 42(1):131-152.

Fernández-Huertas Moraga, J. (2011). New Evidence on Emigrant Selection. Review of Economics and Statistics, 93(1):72-96.

Gould, E. D. and Moav, O. (2014). Does High Inequality Attract High Skilled Immigrants? Economic Journal, forthcoming.

Grogger, J. and Hanson, G. H. (2011). Income Maximization and the Selection and 
Sorting of International Migrants. Journal of Development Economics, 95(1):4257.

Grogger, J. and Hanson, G. H. (2015). Attracting Talent: Location Choices of Foreign-Born PhDs in the US. Journal of Labor Economics, forthcoming.

Grotheer, M., Isleib, S., Netz, N., and Briedies, K. (2012). Hochqualifiziert und gefragt. Ergebnisse der zweiten HIS-HF Absolventenbefragung des Jahrgangs 2005. HIS GmbH.

Heckman, J. J. (1979). Sample Selection Bias as a Specification Error. Econometrica, 47(1):153-161.

Heston, A., Summers, R., and Aten, B. (2012). Penn World Table Version 7.1. Center for International Comparisons of Production, Income and Prices at the University of Pennsylvania.

Hunt, J. (2011). Which Immigrants Are Most Innovative and Entrepreneurial? Distinctions by Entry Visa. Journal of Labor Economics, 29(3):417-457.

Hunt, J. and Gauthier-Loiselle, M. (2010). How Much Does Immigration Boost Innovation? American Economic Journal: Macroeconomics, 2(2):31-56.

Ibarraran, P. and Lubotsky, D. (2007). Mexican Immigration and Self-Selection: New Evidence from the 2000 Mexican Census. In Borjas, G. J., editor, Mexican Immigration to the United States, chapter 5, pages 159-192. University of Chicago Press.

Kaestner, R. and Malamud, O. (2014). Self-Selection and International Migration: New Evidence from Mexico. Review of Economics and Statistics, 96(1):78-91.

Kerr, P. S., Kerr, W. R., and Lincoln, W. F. (2015). Skilled Immigration and the Employment Structures of U.S. Firms. Journal of Labor Economics, forthcoming. Kerr, W. R. and Lincoln, W. F. (2010). The Supply Side of Innovation: H-1B Visa Reforms and U.S. Ethnic Invention. Journal of Labor Economics, 28(3):473-508. Kleven, H. J. and Landais, C. (2013). Taxation and International Migration of Superstars: Evidence from the European Football Market. American Economic Review, 103(5):1892-1924.

Luxembourg Income Study (LIS) (2013). Database (multiple countries). http:// www.lisdatacenter.org.

Moser, P., Voena, A., and Waldinger, F. (2014). German-Jewish Émigrés and US Invention. American Economic Review, 104(10):3222-3255.

OECD (2013a). Glossary of Statistical Terms. http://stats.oecd.org/glossary/.

OECD (2013b). OECD Education at a Glance: OECD Indicators.

OECD (2013c). OECD Tax Statistics, Taxing Wages. http://www.oecd-ilibrary. 
org/taxation/data/taxing-wages_ctpa-twg-data-en;jsessionid=lrtgpce2k79d. $\mathrm{x}$-oecd-live-02.

OECD (2015). Benefits and Wages: Statistcs: Gross Replacement Rates (without Accounting for Taxes), Uneven Years 1961 to 2011. http://www.oecd.org/els/ benefitsandwagesstatistics.htm.

Orrenius, P. M. and Zavodny, M. (2005). Self-Selection among Undocumented Immigrants from Mexico. Journal of Development Economics, 78(1):215-240.

Parey, M. and Waldinger, F. (2011). Studying Abroad and the Effect on International Labor Market Mobility. Economic Journal, 121(551):194-222.

Ramos, F. A. (1992). Outmigration and Return Migration of Puerto Ricans. In Borjas, G. J. and Freeman, R. B., editors, Immigration and the Workforce: Economic Consquences for the United States and Source Areas, chapter 2, pages 49-66. University of Chicago Press.

Roy, A. D. (1951). Some Thoughts on the Distribution of Earnings. Oxford Economic Papers, 3(2):135-146.

Ruggles, S., Alexander, J. T., Genadek, K., Goeken, R., Schroeder, M. B., and Sobeku, M. (2010). Integrated Public Use Microdata Series: Version 5.0 [Machinereadable database].

Silverman, B. W. (1986). Density Estimation for Statistics and Data Analysis. Chapman \& Hall.

Stolz, Y. and Baten, J. (2012). Brain Drain in the Age of Mass Migration: Does Relative Inequality Explain Migrant Selectivity? Explorations in Economic History, 49(2):205-220.

U.S. Bureau of Labor Statistics (2013). Consumer Price Index (CPI) - All Urban Consumers. http://www.bls.gov/cpi/data.htm.

Widmaier, S. and Dumont, J.-C. (2011). Are Recent Immigrants Different? A New Profile of Immigrants in the OECD based on DIOC 2005/06. OECD Social, Employment and Migration Working Papers No. 126. 


\section{A Online Appendix}

\section{A.1 Appendix Tables and Figures}

Table A.1: Data sources for earnings inequality by country

\begin{tabular}{|c|c|c|c|c|}
\hline Country & Data Source & Years & Earnings & Currency \\
\hline Australia & LIS & 1995 (1010), 2001 (752), $2003(1170)$ & gross & Australian Dollar \\
\hline Austria & $\begin{array}{c}\text { LIS } \\
\text { LIS } \\
\text { Microcensus } \\
\text { EU-SILC }\end{array}$ & $\begin{array}{c}1997(121), 2000(97) \\
2004(372) \\
1999(1394) \\
2007(597), 2008(654)\end{array}$ & $\begin{array}{c}\text { net } \\
\text { gross } \\
\text { net } \\
\text { net and gross }\end{array}$ & $\begin{array}{l}\text { Schilling } \\
\text { Euro } \\
\text { Schilling } \\
\text { Euro }\end{array}$ \\
\hline Belgium & LIS & $\begin{array}{l}1997(215) \\
2000(520)\end{array}$ & $\begin{array}{c}\text { gross } \\
\text { net }\end{array}$ & Belgian franc \\
\hline Canada & LIS & 1998 (3236), 2000 (2908), 2004 (3324), 2007 (3669), 2010 (3791) & gross & Canadian Dollar \\
\hline Denmark & LIS & 1995 (9451), 2000 (13464), 2004 (15307) & gross & Danish Krone \\
\hline Finland & LIS & $\begin{array}{c}1995(1275), 2000(1726) \\
2004(6633), 2007(1793), 2010(1683)\end{array}$ & gross & $\begin{array}{l}\text { Finish Markka } \\
\text { Euro }\end{array}$ \\
\hline France & LIS & $\begin{array}{c}1994(728), 2000(675) \\
2005(1115)\end{array}$ & net & $\begin{array}{l}\text { French Franc } \\
\text { Euro }\end{array}$ \\
\hline Germany & LIS & $\begin{array}{c}1994(822), 2000(1511) \\
2004(1622), 2007(1529), 2010(1536)\end{array}$ & gross & $\begin{array}{l}\text { Deutsche Mark } \\
\text { Euro }\end{array}$ \\
\hline Ireland & LIS & $\begin{array}{c}1996(150), 2000(148) \\
2004(610), 2007(1529), 2010(1536) \\
\end{array}$ & $\begin{array}{c}\text { net } \\
\text { gross }\end{array}$ & $\begin{array}{l}\text { Irish Pound } \\
\text { Euro }\end{array}$ \\
\hline Italy & LIS & $\begin{array}{r}1998(418), 2000(493) \\
2004(440), 2008(633), 2010(739)\end{array}$ & net & $\begin{array}{l}\text { Italian Lira } \\
\quad \text { Euro }\end{array}$ \\
\hline Japan & LIS & $2008(841)$ & gross & Yen \\
\hline Luxembourg & LIS & $\begin{aligned} 1997 & (297), 2000(391) \\
2004(720), & 2007(780), 2010(953)\end{aligned}$ & $\begin{array}{l}\text { net } \\
\text { gross }\end{array}$ & $\begin{array}{l}\text { Luxembourg Franc } \\
\text { Euro }\end{array}$ \\
\hline Netherlands & LIS & $\begin{array}{c}1993(687), 1999(772) \\
2004(1801), 2007(2127), 2010(2236) \\
\end{array}$ & gross & $\begin{array}{l}\text { Netherlands Guilder } \\
\text { Euro }\end{array}$ \\
\hline Norway & LIS & 1995 (2031), 2000 (3501), 2004 (3920) & gross & Norwegian Krone \\
\hline Poland & LIS & $\begin{array}{c}1995(2642) \\
2007(4381), 2010(6358)\end{array}$ & $\begin{array}{l}\text { net } \\
\text { gross }\end{array}$ & Zloty \\
\hline Spain & LIS & $\begin{array}{c}1995(579), 2000(528) \\
2004(2318) \\
2007(2175), 2010(2138)\end{array}$ & $\begin{array}{c}\text { net } \\
\text { net } \\
\text { gross }\end{array}$ & $\begin{array}{c}\text { Spanish Peseta } \\
\text { Euro } \\
\text { Euro } \\
\end{array}$ \\
\hline Sweden & LIS & 1995 (2427), 2000 (3115), 2005 (2605) & gross & Swedish Krona \\
\hline Switzerland & SAKE & 1998-2005 (2394) & net and gross & Swiss Franc \\
\hline UK & LIS & 1995 (459), 1999 (2840), 2004 (3379), 2007 (3233), 2010 (3610) & gross & Pound Sterling \\
\hline United States & LIS & 1997 (12988), 2000 (13443), 2004 (23229), 2007 (24295), 2010 (24026) & gross & US Dollar \\
\hline
\end{tabular}

Notes: Numbers in parentheses give the number of (unweighted) observations of university graduates, 30 to 60 years old, working in full-time dependent employment, with strictly positive earnings. For Switzerland, we report the average number of observations over all years. The main data source is the Luxembourg Income Study (LIS). For Austria and Switzerland, we use additional surveys. Austria: Microcensus (1999) and Survey on Income and Living Conditions (EU-SILC) (2007, 2008). Switzerland: Swiss Labour Force Survey (SAKE) (1998-2005). LIS contains different surveys for the countries: Australia: Survey of Income and Housing Costs (SIHC); Austria: European Household Panel (ECHP) (1997, 2000), Survey of Income and Living Conditions (EU-SILC) (2004); Belgium: Socio-Economic Panel (SEP) (1997), Panel Study of Belgian Households (PSBH) (2000); Canada: Survey of Labour and Income Dynamics (SLID); Denmark: Income Tax Register; Finland: Income Distribution Survey (IDS) (1995, 2000, 2004), Survey on Income and Living Conditions (EU-SILC) (2007, 2010); France: Family Budget Survey (BdF); Germany: German Social Economic Panel Study (GSOEP); Ireland: Living in Ireland Survey (ECHP) (1996, 2000), Survey on Income and Living Conditions (EU-SILC) (2004, 2007, 2010); Italy: Survey on Household Income and Wealth (SHIW); Japan: Japan Household Panel Survey Data (JHPS); Luxembourg: Socio-Economic Panel Living in Luxembourg (PSELL); Netherlands: Socio-Economic Panel Survey (1999, 2004), Survey on Income and Living Conditions (EU-SILC) (2004, 2007, 2010); Norway: Income Distribution Survey (IF); Poland: Household Budget Survey; Spain: Spanish European Community Household Panel (ECHP) (1995, 2000), Survey on Income and Living Conditions (EU-SILC) (2004, 2007, 2010); Sweden: Income Distribution Survey (HINK); UK: Family Resources Survey (FRS); United States: Current Population Survey (CPS). 
Table A.2: Inequality measures

\begin{tabular}{lcccc}
\hline & $(1)$ & $(2)$ & $(3)$ & $(4)$ \\
\hline Country & $\begin{array}{c}75 / 25 \text { ratio } \\
\text { graduates }\end{array}$ & $\begin{array}{c}75 / 25 \text { ratio } \\
\text { full population }\end{array}$ & $\begin{array}{c}90 / 50 \text { ratio } \\
\text { full population }\end{array}$ & $\begin{array}{c}\text { Gini, OECD } \\
\text { full population }\end{array}$ \\
\hline United States & 1.930 & 2.070 & 2.085 & 0.362 \\
France & 1.889 & 1.736 & 1.890 & 0.288 \\
Poland & 1.873 & 1.884 & 1.960 & 0.322 \\
Italy & 1.806 & 1.445 & 1.639 & 0.317 \\
Spain & 1.766 & 1.790 & 1.877 & 0.316 \\
Japan & 1.749 & 2.084 & 1.742 & 0.326 \\
Canada & 1.733 & 1.954 & 1.872 & 0.323 \\
United Kingdom & 1.724 & 1.866 & 1.961 & 0.340 \\
Austria & 1.650 & 1.721 & 1.717 & 0.263 \\
Luxembourg & 1.553 & 1.915 & 1.788 & 0.275 \\
Switzerland & 1.551 & 1.598 & 1.663 & 0.290 \\
Belgium & 1.540 & 1.467 & 1.580 & 0.261 \\
Germany & 1.524 & 1.476 & 1.625 & 0.276 \\
Ireland & 1.521 & 1.596 & 1.686 & 0.307 \\
Sweden & 1.467 & 1.427 & 1.497 & 0.255 \\
Netherlands & 1.450 & 1.406 & 1.590 & 0.290 \\
Australia & 1.439 & 1.501 & 1.622 & 0.310 \\
Norway & 1.409 & 1.461 & 1.514 & 0.262 \\
Finland & 1.395 & 1.342 & 1.581 & 0.256 \\
Denmark & 1.347 & 1.314 & 1.437 & 0.230 \\
\hline Correlation with $75 / 25$ ratio (graduates) & 1.000 & 0.755 & 0.864 & 0.748 \\
\hline
\end{tabular}

Notes: The inequality measures reported in column (1) (75/25 ratio graduates) are computed from a sample of university graduates, working full-time, 30-60 years old, based on net earnings. Inequality measures reported in columns (2) and (3) are computed for the full population. Column (4) reports average Gini coefficients based on earnings for the full population. All inequality measures are averaged for the time period 1998-2010. Data for the measures reported in columns (1) to (3) come from the Luxembourg Income Study (LIS) for most countries, from the Microcensus and EU-SILC for Austria, and from SAKE for Switzerland. Data on Gini coefficients reported in column (4) come from the OECD. See Appendix B.1 for details. 
Table A.3: Stochastic dominance tests

\begin{tabular}{|c|c|c|c|}
\hline & \multirow[b]{2}{*}{$\begin{array}{c}\text { Test } \\
\text { statistic }\end{array}$} & \multicolumn{2}{|c|}{$p$-value } \\
\hline & & $\begin{array}{c}\text { Kolmogorov- } \\
\text { Smirnov }\end{array}$ & $\begin{array}{l}\text { Barrett- } \\
\text { Donald }\end{array}$ \\
\hline & $(1)$ & $(2)$ & $(3)$ \\
\hline \multicolumn{4}{|c|}{ Panel A: Selection to more equal and less equal destinations } \\
\hline \multicolumn{4}{|c|}{ Panel A1: OLS } \\
\hline 'Home' vs 'Equal' & -0.014 & 0.963 & 0.988 \\
\hline 'Unequal' vs 'Home' & 0.000 & 1.000 & 1.000 \\
\hline 'Unequal' vs 'Equal' & -0.004 & 0.997 & 0.998 \\
\hline \multicolumn{4}{|c|}{ Panel A2: Heckman selection correction } \\
\hline 'Home' vs 'Equal' & -0.015 & 0.956 & 0.971 \\
\hline 'Unequal' vs 'Home' & 0.000 & 1.000 & 1.000 \\
\hline 'Unequal' vs 'Equal' & -0.004 & 0.997 & 1.000 \\
\hline \multicolumn{4}{|c|}{ Panel B: Selection to very equal and very unequal destinations } \\
\hline \multicolumn{4}{|c|}{ Panel B1: OLS } \\
\hline 'Home' vs 'Very equal' & -0.016 & 0.981 & 0.990 \\
\hline 'Very unequal' vs 'Home' & -0.010 & 0.975 & 0.993 \\
\hline 'Very unequal' vs 'Very equal' & 0.000 & 1.000 & 1.000 \\
\hline \multicolumn{4}{|c|}{ Panel A2: Heckman selection correction } \\
\hline 'Home' vs 'Very equal' & -0.018 & 0.977 & 0.976 \\
\hline 'Very unequal' vs 'Home' & -0.010 & 0.975 & 0.991 \\
\hline 'Very unequal' vs 'Very equal' & 0.000 & 1.000 & 0.999 \\
\hline
\end{tabular}

Notes: Table reports one-sided Kolmogorov-Smirnov test statistic and Kolomogorov-Smirnov and Barrett and Donald $p$-values. Barrett and Donald $p$-values are bootstrapped, following equation (11) in Barrett and Donald (2003, p. 82). In the top row ('Home' versus 'Equal'), we test the null hypothesis that the CDF of non-migrants stochastically dominates the CDF of migrants to more equal destination, and similarly for the other cells. Bootstrap based on 4,999 replications. See text for details. 
Table A.4: Stochastic dominance tests for selected destinations

\begin{tabular}{|c|c|c|c|c|}
\hline & \multirow[b]{2}{*}{$\begin{array}{c}\text { Test } \\
\text { statistic } \\
(1)\end{array}$} & \multicolumn{3}{|c|}{$p$-value } \\
\hline & & $\begin{array}{l}\text { Kolmogorov- } \\
\text { Smirnov } \\
(2)\end{array}$ & \multicolumn{2}{|c|}{$\begin{array}{l}\text { Barrett- } \\
\text { Donald } \\
(3)\end{array}$} \\
\hline \multicolumn{5}{|c|}{$\begin{array}{l}\text { Panel A: Restrict destinations to } E U \text { (2005) } \\
\text { as well as Norway and Switzerland }\end{array}$} \\
\hline \multicolumn{5}{|c|}{ Panel A1: $O L S$} \\
\hline 'Equal' vs 'Home' & 0.206 & $0.001 \quad * * *$ & 0.003 & $* * *$ \\
\hline 'Home' vs 'Unequal' & 0.052 & 0.133 & 0.289 & \\
\hline 'Equal' vs 'Unequal' & 0.231 & $0.000 \quad * * *$ & 0.002 & $* * *$ \\
\hline \multicolumn{5}{|c|}{ Panel A2: Heckman selection correction } \\
\hline 'Equal' vs 'Home' & 0.201 & $0.001 \quad * * *$ & 0.016 & $* *$ \\
\hline 'Home' vs 'Unequal' & 0.061 & $0.061 *$ & 0.187 & \\
\hline 'Equal' vs 'Unequal' & 0.231 & $0.000 \quad * * *$ & 0.003 & $* * *$ \\
\hline \multicolumn{5}{|c|}{ Panel B: Selection to Austria and Switzerland } \\
\hline \multicolumn{5}{|c|}{ Panel B1: OLS } \\
\hline 'Home' vs 'Austria/Switzerland' & 0.095 & $0.031 * *$ & 0.090 & $*$ \\
\hline \multicolumn{5}{|c|}{ Panel B2: Heckman selection correction } \\
\hline 'Home' vs 'Austria/Switzerland' & 0.102 & $0.019 * *$ & 0.075 & $*$ \\
\hline \multicolumn{5}{|c|}{ Panel C: Selection to the United States } \\
\hline \multicolumn{5}{|c|}{ Panel C1: $O L S$} \\
\hline 'Home' vs 'United States' & 0.173 & $0.006 \quad * * *$ & 0.033 & $* *$ \\
\hline \multicolumn{5}{|c|}{ Panel C2: Heckman selection correction } \\
\hline 'Home' vs 'United States' & 0.191 & $0.002 \quad * * *$ & 0.022 & $* *$ \\
\hline
\end{tabular}

Notes: Table reports one-sided Kolmogorov-Smirnov test statistic and Kolomogorov-Smirnov and Barrett and Donald $p$-values. Barrett and Donald $p$-values are bootstrapped, following equation (11) in Barrett and Donald (2003, p. 82). In the top row ('Equal' versus 'Home'), we test the null hypothesis that the CDF of migrants to more equal destinations stochastically dominates the CDF of non-migrants, and similarly for the other cells. Bootstrap based on 4,999 replications. See text for details. 
Table A.5: Mincer regressions for U.S. native university graduates in the United States

\begin{tabular}{|c|c|c|c|c|c|}
\hline Dependent variable: Labor earnings & (1) & $(2)$ & $(3)$ & $(4)$ & (5) \\
\hline \multicolumn{6}{|l|}{ University degree } \\
\hline Master's degree & $\begin{array}{c}0.128^{* * *} \\
(0.002)\end{array}$ & $\begin{array}{c}0.177^{* * *} \\
(0.002)\end{array}$ & $\begin{array}{c}0.177^{* * *} \\
(0.002)\end{array}$ & $\begin{array}{c}0.186^{* * *} \\
(0.002)\end{array}$ & $\begin{array}{c}0.184^{* * *} \\
(0.002)\end{array}$ \\
\hline Professional degree beyond a bachelor's degree & $\begin{array}{c}0.562^{* * *} \\
(0.005)\end{array}$ & $\begin{array}{c}0.570^{* * *} \\
(0.005)\end{array}$ & $\begin{array}{c}0.569^{* * *} \\
(0.005)\end{array}$ & $\begin{array}{c}0.558^{* * *} \\
(0.005)\end{array}$ & $\begin{array}{c}0.550^{* * *} \\
(0.005)\end{array}$ \\
\hline Doctoral degree & $\begin{array}{c}0.289^{* * * *} \\
(0.006)\end{array}$ & $\begin{array}{c}0.301^{* * *} \\
(0.006)\end{array}$ & $\begin{array}{c}0.300^{* * *} \\
(0.006)\end{array}$ & $\begin{array}{c}0.290^{* * * *} \\
(0.006)\end{array}$ & $\begin{array}{c}0.286^{* * *} \\
(0.006)\end{array}$ \\
\hline \multicolumn{6}{|l|}{ Age } \\
\hline Age & & & $\begin{array}{c}0.128^{* * *} \\
(0.007)\end{array}$ & $\begin{array}{c}0.115^{* * *} \\
(0.007)\end{array}$ & $\begin{array}{c}0.092^{\text {*** }} \\
(0.007)\end{array}$ \\
\hline Age square & & & $\begin{array}{c}-0.001^{* * *} \\
(0.000)\end{array}$ & $\begin{array}{c}-0.001^{* * *} \\
(0.000)\end{array}$ & $\begin{array}{c}-0.001^{* * *} \\
(0.000)\end{array}$ \\
\hline \multicolumn{6}{|l|}{ Female } \\
\hline Female & & & & $\begin{array}{c}-0.239^{* * *} \\
(0.002)\end{array}$ & $\begin{array}{c}-0.224^{\text {**** }} \\
(0.002)\end{array}$ \\
\hline \multicolumn{6}{|l|}{ Partner/Children } \\
\hline Married & & & & & $\begin{array}{c}0.109^{* * *} * \\
(0.003)\end{array}$ \\
\hline Children & & & & & $\begin{array}{c}0.044^{* * *} * \\
(0.002)\end{array}$ \\
\hline Constant & $\begin{array}{c}11.172^{* * * *} \\
(0.002)\end{array}$ & $\begin{array}{c}11.029^{* * *} \\
(0.009)\end{array}$ & $\begin{array}{c}8.088^{* * *} \\
(0.138) \\
\end{array}$ & $\begin{array}{c}8.428^{* * *} \\
(0.136) \\
\end{array}$ & $\begin{array}{c}8.772^{\text {*** }} \\
(0.136)\end{array}$ \\
\hline Graduate cohort FE & YES & YES & YES & YES & YES \\
\hline Subject FE & & YES & YES & YES & YES \\
\hline R-sq. & 0.096 & 0.177 & 0.179 & 0.212 & 0.222 \\
\hline Observations & 289,538 & 289,538 & 289,538 & 289,538 & 289,538 \\
\hline
\end{tabular}

Notes: The table shows Mincer regressions for U.S. natives. See section B.3 for details on the sample construction and data source. Robust standard errors in parentheses. Significance levels: ${ }^{* * *} \mathrm{p}<0.01,{ }^{* *} \mathrm{p}<0.05,{ }^{*} \mathrm{p}<0.1$. 
Figure A.1: Design of DZHW Graduate Panels

\begin{tabular}{|c|c|c|c|c|c|c|c|c|c|c|c|c|c|c|c|c|c|c|c|c|}
\hline \multirow{2}{*}{$\begin{array}{l}\text { Graduate } \\
\text { Cohort }\end{array}$} & \multirow{2}{*}{92} & \multirow[b]{2}{*}{93} & \multirow[b]{2}{*}{94} & \multirow[b]{2}{*}{95} & \multirow[b]{2}{*}{96} & \multirow[b]{2}{*}{97} & \multirow[b]{2}{*}{98} & \multirow[b]{2}{*}{99} & \multirow[b]{2}{*}{00} & \multirow[b]{2}{*}{01} & \multirow[b]{2}{*}{02} & \multirow[b]{2}{*}{03} & \multirow[b]{2}{*}{04} & \multirow[b]{2}{*}{05} & \multirow[b]{2}{*}{06} & \multirow[b]{2}{*}{07} & \multirow[b]{2}{*}{08} & \multirow[b]{2}{*}{09} & \multirow[b]{2}{*}{10} & \multirow[b]{2}{*}{11} \\
\hline & & & & & & & & & & & & & & & & & & & & \\
\hline 1993 & 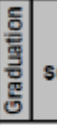 & $\begin{array}{l}\text { 1st } \\
\text { survey }\end{array}$ & & & & & $\begin{array}{l}\text { Follo } \\
\text { Sur }\end{array}$ & veyp & & & & & & & & & & & & \\
\hline 1997 & & & & & & 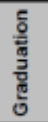 & $\begin{array}{l}\text { 1st } \\
\text { Surv } \\
\text { ey }\end{array}$ & & & & & & & & & & & & & \\
\hline 2001 & & & & & & & & & & 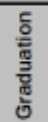 & \begin{tabular}{|c} 
1st \\
Surv \\
ey
\end{tabular} & & & & & & & & & \\
\hline 2005 & & & & & & & & & & & & & & 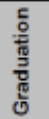 & $\begin{array}{l}\text { 1st } \\
\text { Surv } \\
\text { ey }\end{array}$ & & & & & $\begin{array}{l}\text { W-Up } \\
\text { vey }\end{array}$ \\
\hline
\end{tabular}

Notes: The figure shows the timing of the baseline and the five-year follow-up surveys of the DZHW Graduate Panels. 


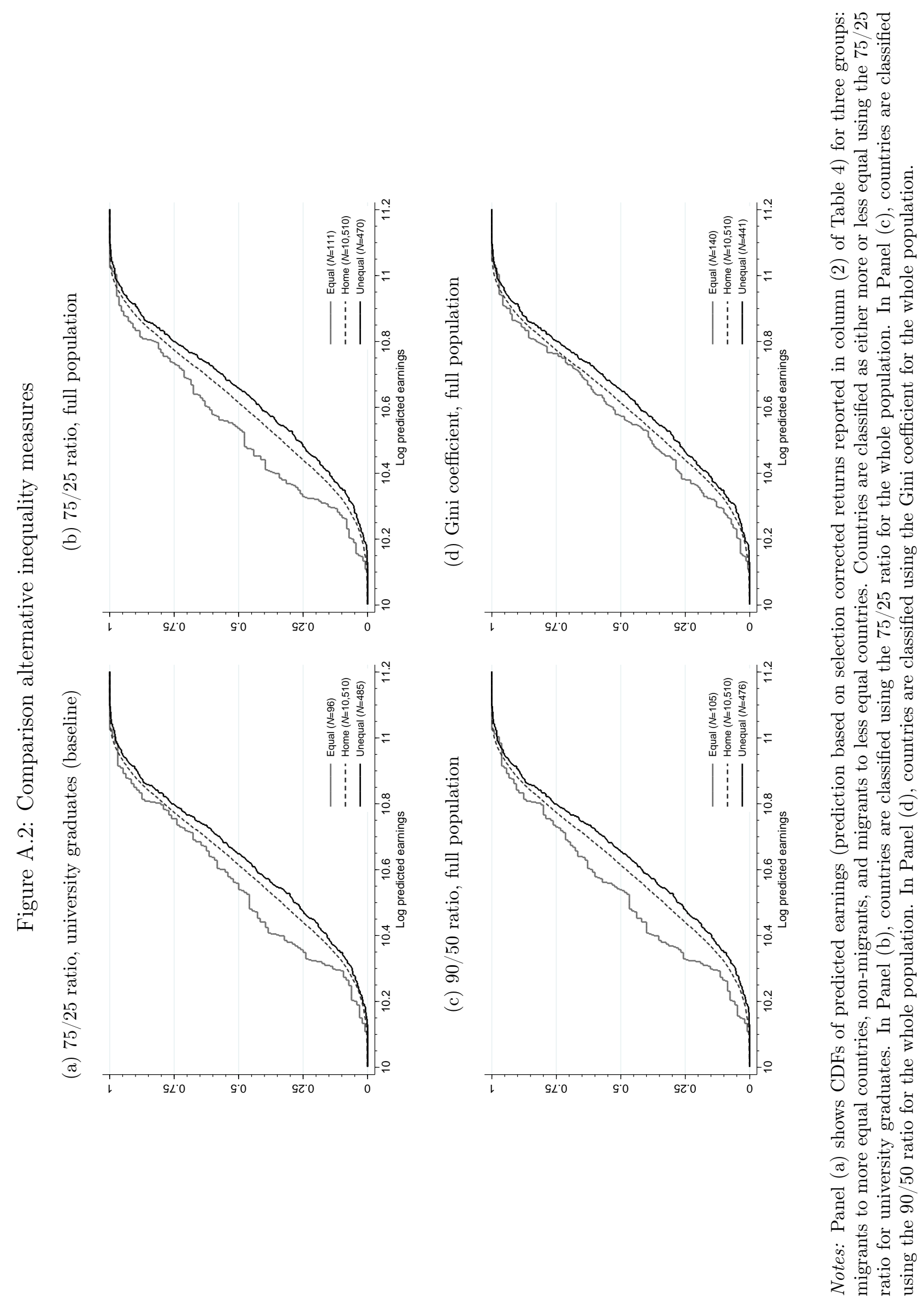




\section{A.2 Bootstrap Test for Differences between the CDFs}

In this section, we describe the bootstrap procedure that we implement to test differences between CDFs of earnings potential. We adapt the method developed by Barrett and Donald (2003) to our application. To facilitate the exposition, we denote the number of stayers by $N^{\text {Home }}$, the number of individuals observed in less equal destinations by $N^{\text {Unequal }}$, and the number of individuals observed in more equal destinations by $N^{\text {Equal }}$. We use the following bootstrap procedure:

1. Draw a sample of size $N^{\text {Home }}$ from the sample of stayers, with replacement. Similarly, draw samples of sizes $N^{\text {Unequal }}$ and $N^{\text {Equal }}$ from the migrants observed in less and in more equal destinations, respectively. These data form the bootstrap sample $b$, which we denote with a star $\left(^{\star}\right)$.

2. Use the bootstrap sample to estimate the Mincer wage regression, resulting in a coefficient estimate of $\hat{\beta}^{\star}$. Predict earnings potential for every observation in the bootstrap sample, $\hat{\theta}_{0 i}^{\star}$ Construct the corresponding CDFs of earnings potential in each destination,

$$
F^{\star}\left(\hat{\theta}_{0}^{\star} \mid \text { Migration status }\right) \text {. }
$$

3. As an example, we focus on the test between 'Home' and 'Unequal' destinations. Following equation (11) in Barrett and Donald (2003), construct the test statistic

$$
\begin{aligned}
& \bar{S}_{b}^{\text {Unequal, Home }}= \\
& \sup _{z}\left[\left(F^{\star}(z \mid \text { Home })-F^{\star}(z \mid \text { Unequal })\right)-(F(z \mid \text { Home })-F(z \mid \text { Unequal }))\right] .
\end{aligned}
$$

(The second difference in the test statistic re-centers the bootstrapped CDF against the main estimate of the CDF.)

4. Repeat steps 1-3 many times using $B$ replications $(b=1 \ldots B)$.

The main estimate for the difference between the two CDFs of interest is as follows: ${ }^{43}$

$$
\bar{S}^{\text {Unequal, Home }}=\sup _{z}(F(z \mid \text { Home })-F(z \mid \text { Unequal }))
$$

\footnotetext{
${ }^{43}$ Note that Barrett and Donald (2003) present the test statistic with an additional factor depending on the relevant sample sizes only. We omit this factor here because it applies symmetrically to the bootstrap samples and the main test statistic; this does not affect the result.
} 
The resulting bootstrap $p$-value then is

$$
\hat{p}^{\text {Unequal, Home }}=\frac{1}{B} \sum_{b=1}^{B} 1\left[\bar{S}_{b}^{\text {Unequal, Home }}>\bar{S}^{\text {Unequal, Home }}\right] .
$$

For the selection-corrected estimates, we apply the same procedure, using the Heckman selection-correction to compute the coefficient estimate $\hat{\beta}^{\star}$. ${ }^{44}$

\footnotetext{
${ }^{44}$ The sampling procedure sometimes results in bootstrap samples where an institution is only represented by stayers. In the case of the selection-corrected estimates, these observations drop out of the sample in the probit stage because we include institution fixed effects. The resulting bootstrap samples therefore tend to be slightly smaller than the main sample in the case where we correct for sample-selection.
} 


\section{B Data Appendix}

\section{B.1 Construction of Inequality Measures}

\section{B.1.1 Data Sources on Earnings in Germany and Destination Countries}

We collect data on $75 / 25$ earnings differentials for the main destinations from the Luxembourg Income Study (LIS) (2013). Two important destinations for German university graduates, Austria and Switzerland, are not comprehensively covered in the LIS. We therefore use additional datasets for these countries: for Austria, the Microcensus (1999) and the European Union Statistics on Income and Living Conditions (EU-SILC) (2007 and 2008), and for Switzerland, the Schweizerische Arbeitskräfteerhebung (SAKE) (1998-2005) to collect data on additional years. Table A.1 summarizes the data sources, available survey years, and the number observations in each survey and year.

We then construct earnings inequality measures for the period 1998 to $2010 .{ }^{45} \mathrm{We}$ restrict the samples to full-time employed men and women between 30 and 60 years, exclude self-employed individuals, individuals who are still in school, and individuals who report zero or negative earnings. We apply the sampling weights of the surveys to calculate all statistics. Using these samples, we then construct earnings percentiles based on personal annual labor income.

To compare wage levels across countries, we convert each currency to U.S. dollars adjusted by purchasing-power-parity (ppp) measures from the Penn World Table (Heston et al., 2012). To express earnings in constant prices, we use the U.S. consumer price index for urban consumers from the U.S. Bureau of Labor Statistics (2013). These adjustments do not affect our inequality measures because inequality measures are based on percentile ratios and all adjustments cancel out when we compute ratios. Figure B.1 shows mean earnings by country and year for university graduates. Each dot represents one underlying survey in the LIS data and our additional data sources. As indicated by the figure, some surveys report gross earnings while others report net earnings.

\section{B.1.2 Constructing Measures of Net Earnings Using OECD Tax Data}

We construct a consistent time series of net earnings by converting gross earnings into net earnings using tax rates from the OECD (2013c). The OECD reports three

\footnotetext{
${ }^{45}$ We calculate yearly earnings by muliplying monthly earnings by 12 for surveys that only report monthly earnings. The Austrian Microcensus only reports total income from all sources; we use this income measure to compute inequality.
} 
tax rates for different positions in the earnings distribution. Tax rates for individuals with earnings equal to 67 percent, 100 percent, and 167 percent of average earnings. ${ }^{46}$ From 2000 to 2010, the OECD reports tax rates for average workers (AW) ${ }^{47}$. Before 2000 , the OECD only reports tax rates for average production workers (APW) ${ }^{48}$. As the definition of average workers includes white collar workers, average worker tax rates are closer to tax rates paid by university graduates. We construct tax rates for average workers (AW) for 1998 and 1999 using data from 2000 to 2004 - a period when the OECD reported tax rates for both APW and AW. ${ }^{49}$ First, we regress the tax rate for AWs on the tax rate for APWs including country and time fixed effects for the period 2000 to 2004 . We then use the estimated coefficients to predict tax rates for AWs for 1998 and 1999. Figure B.2 reports tax rates for workers with earnings equal to 67 percent, 100 percent, and 167 percent of average earnings.

\section{B.1.3 Construct 75/25 Differentials Based on Net Earnings}

We construct earnings percentiles based on net earnings for each country and year between 1998 to 2010 by linearly interpolating percentiles for years with missing data. At endpoints, we extrapolate using the same value as in the last observed survey. ${ }^{50}$ Table B.1 reports mean earnings, 25th, 50th, and 75th earnings percentiles for each country. We classify countries into either more or less equal destinations using average 75/25 differentials for the time period 1998 to 2010.

\footnotetext{
${ }^{46}$ We use tax rates for single persons without children because some surveys in the LIS data do not provide coherent information about household compositions. The majority of university graduates in the graduate cohort data are not married and do not have children. For the minority of graduates who are married and/or have children, tax rates for single persons without children may be too high. Nevertheless, these tax rates give a good indication of the general tax incidence in a country.

${ }^{47}$ The average worker (AW) is defined as "an adult full-time worker in the private sector whose wage earnings are equal to the average wage earnings of such workers. This definition includes manual and non-manual workers, supervisory workers as well as managerial workers." (OECD, 2013a)

${ }^{48}$ The average production worker (APW) is defined as "an adult full-time worker directly engaged in a production activity within the manufacturing sector whose earnings are equal to the average wage earnings of such workers. This definition includes manual workers and minor shop-floor supervisory workers. White collar workers are excluded." (OECD, 2013a).

${ }^{49}$ During this period, the two series are highly correlated ( 0.94 for the tax rate of 100 percent of average earnings).

${ }^{50}$ For countries that report data for the pre-1998 period, we use the information in these early surveys to linearly interpolate between the last pre-1998 survey and the first post-1998 survey to obtain percentiles for years until the first available post-1998 survey.
} 


\section{B.1.4 Comparison of Average Wages}

To verify the reliability of the augmented LIS data, we compare mean earnings (for the whole population) with official statistics from the OECD. In Figure B.3, we plot gross earnings averaged over the period from 1998 to 2010 against mean earnings from the OECD. The OECD data are ppp-adjusted and denoted in 2013 U.S. dollars and 2013 constant prices. Average annual earnings are computed per full-time equivalent dependent employee. The number is obtained by dividing the national-accounts-based total wage bill by the average number of employees in the total economy, which is then multiplied by the ratio of average usual weekly hours per full-time employee to average usually weekly hours for all employees. As it is evident from the figure, the correlation between the two series is very high $(r=0.899)$.

\section{B.2 Data on Confounding Factors}

Table B.2 shows country-level values used in section 4.1. Unemployment rates are unemployment rates of 25-64 year-olds with tertiary education. Data come from the OECD and are taken from two editions of Education at a Glance. For the years 1998 to 2009, we take the 2011 edition (Table A7.4a, p. 131 and 132) and for the year 2010, we take the 2014 edition (Table A5.2a, p. 117). Family expenditure are public expenditures on family benefits, such as child allowances and credits, childcare support, income support during leave, and sole parent payments, as percent of GDP and they are taken from the OECD Social Expenditure Database (SOCX). We have yearly data on both series and take simple averages over the years 1998 to 2010. Life satisfaction is a component of the OECD Better Life Index 2014 and is an average score which considers people's evaluation of their life as a whole. It is a weighted-sum of different response categories based on people's rates of their current life relative to the best and worst possible lives for them on a scale from 0 to 10, using the Cantril Ladder (known also as the "Self-Anchoring Striving Scale"). The reference year is 2013 for all countries with the exception of 2012 for Norway, Switzerland, and the United States, and 2011 for Japan.

\section{B.3 German Immigrants in the American Community Sur- vey (ACS)}

To identify high-skilled migrants from Germany in the United States, we use data from the American Community Survey (ACS). The data come from the Integrated Public Use Microdata Series (IPUMS) from the Minnesota Population Center (Rug- 
gles et al., 2010). The ACS is an administrative, yearly, and cross-sectional survey designed to collect representative information on the U.S. population between the ten year Census surveys. It covers 1 percent of the U.S. population. To maximize sample size, we use the 2011 ACS three-year sample, which pools the 2009, 2010, and 2011 ACS waves. We are restricted to use 2009 as the oldest survey because the field of study, which we need for our Mincer regression, is collected and reported in that year for the first time.

Our sample contains only those either born in the United States or in Germany. For both groups, we keep only those between 30 and 45 years of age, who are full-time employed (worked 50 and 52 weeks per year and more than 35 hours a week) and have at least a (four-year) bachelor's degree. We drop all individuals with missing earnings information and zero earnings. After these restrictions, there are a few cases who report very low annual earnings. Therefore, we further drop the lowest 1 percentile of the earnings distribution. This is mainly for expositional purposes and does not affect the results.

We want to identify German immigrants who belong to the same graduate cohorts as the cohorts that we observe in the DZHW data. Thus, we require that the migrant migrated between 1996 and 2010 and is at least 25 years old at the time of immigration. The age restriction is to ensure that the migrants received their education in Germany. We drop all those migrants from the sample who report that their parents are U.S. citizens. We construct cohort dummies for the four survey rounds and assign German immigrants and U.S. natives between 42 and 45 years of age to graduate cohort 1993, those between 38 and 41 years of age to graduate cohort 1997, those between 34 and 37 years of age to graduate cohort 2001, and those between 30 and 33 years of age to graduate cohort 2005.

The final sample contains 565 German immigrants and 289,538 U.S. natives. 


\section{B.4 Figures and Tables}

Figure B.1: Mean of weighted gross and net earnings in ppp-adjusted 2005 U.S. dollars

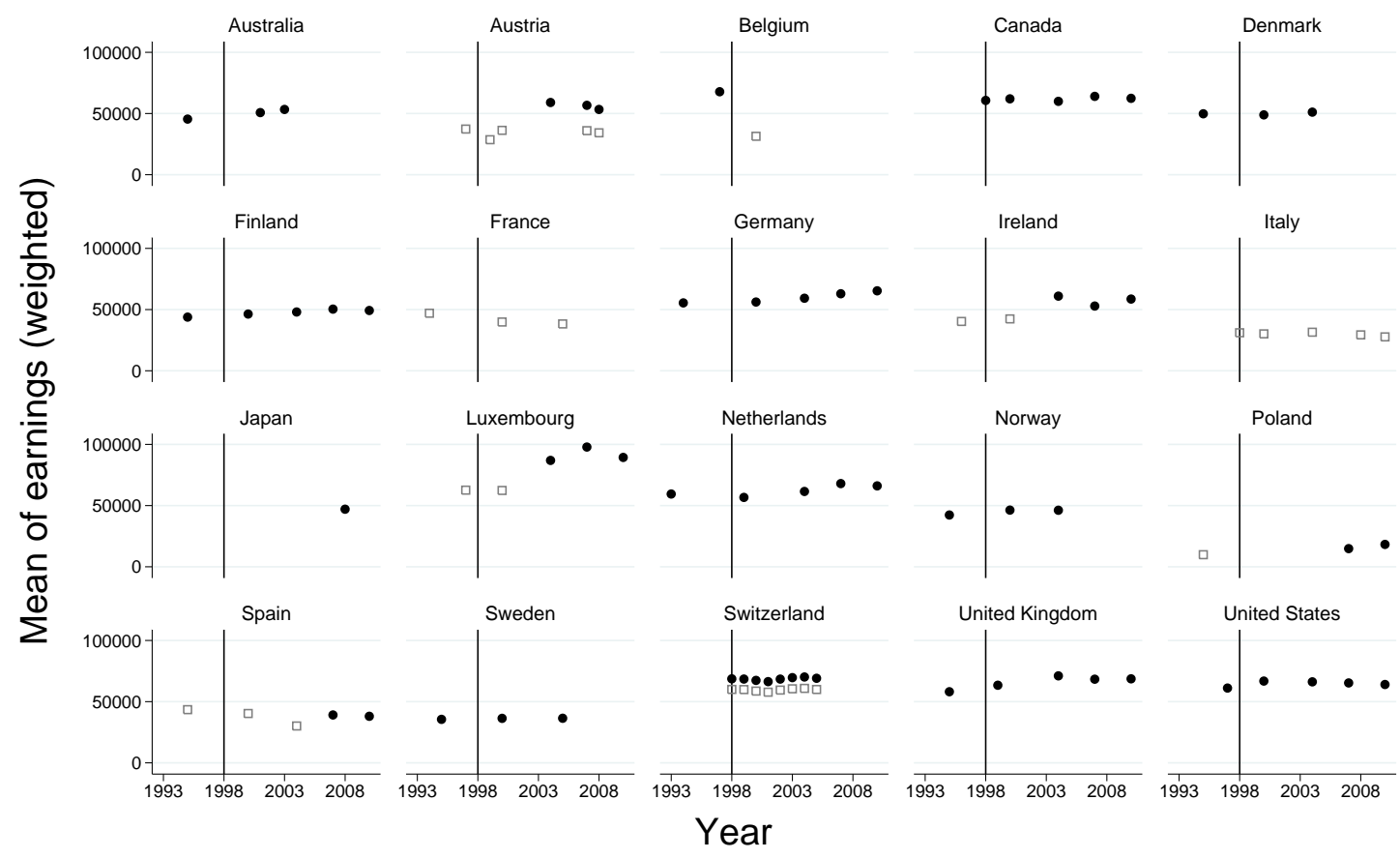

\section{- Gross earnings $\square$ Net earnings}

Personal annual labor earnings

Notes: The figure shows mean values of weighted gross and net earnings in ppp-adjusted 2005 U.S. dollars over countries and years for university graduates. We use the U.S. consumer price index to convert current dollars in constant 2005 dollars (U.S. Bureau of Labor Statistics, 2013). Purchasingpower-parity measures are from Heston et al. (2012). Pre-2002 earnings are adjusted to Euro values for Euro countries. For each country, the sample is restricted to full-time employed university graduates who are between 30 and 60 years. We only consider regular or dependent employment. Data are collected from the Luxembourg Income Study (LIS) (2013) and from additional income surverys for Austria and Switzerland. The horizontal line indicates the year 1998, the first year for which we observe German university graduates. 
Figure B.2: Tax rate series
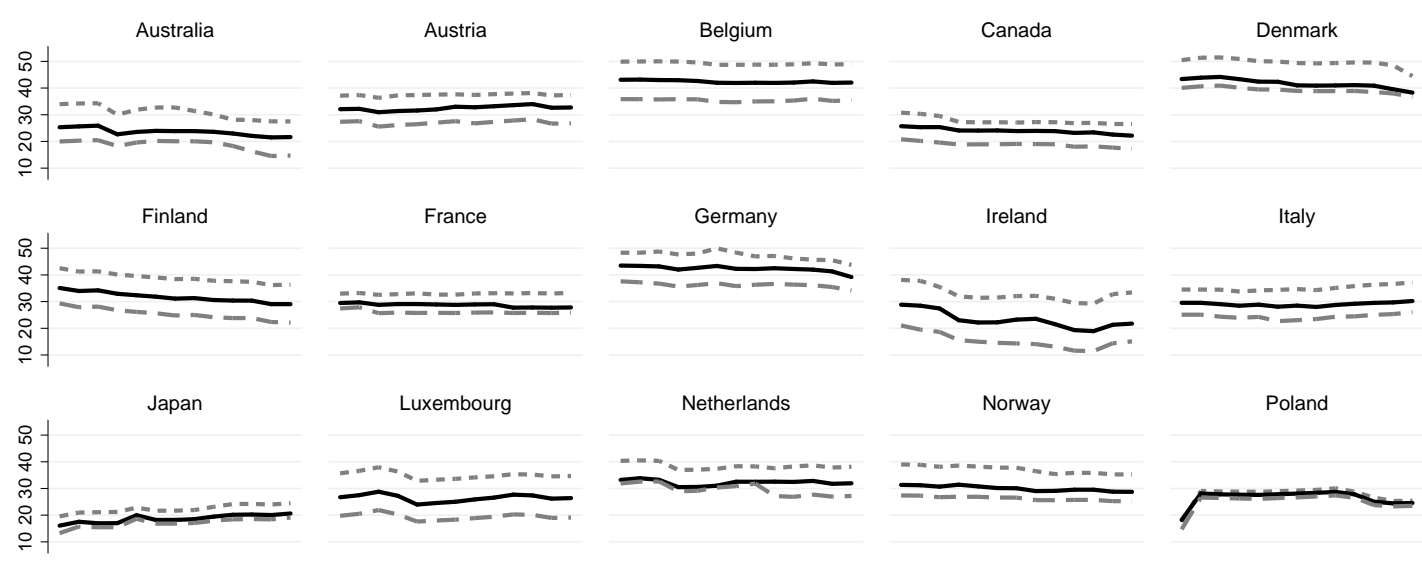

Luxembourg

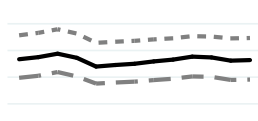

Sweden

Germany

Ireland
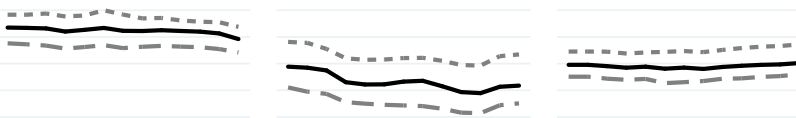

Italy
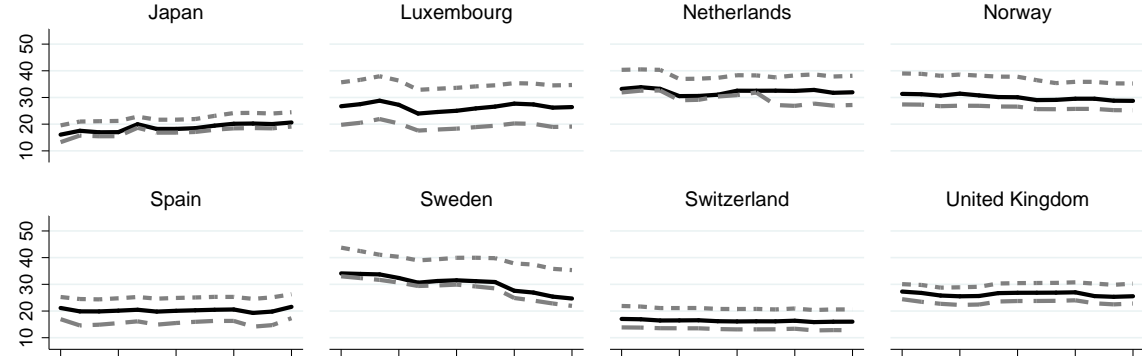

Poland

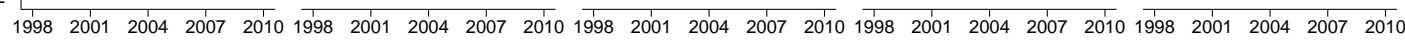

Year

\section{..... Tax at 167 percent of average earnings \\ Tax at 100 percent of average earnings \\ Tax at 67 percent of average earnings}

Notes: The figure shows the time series for the tax data in each country. Data come from OECD (2013c). 
Figure B.3: Comparison of mean earnings

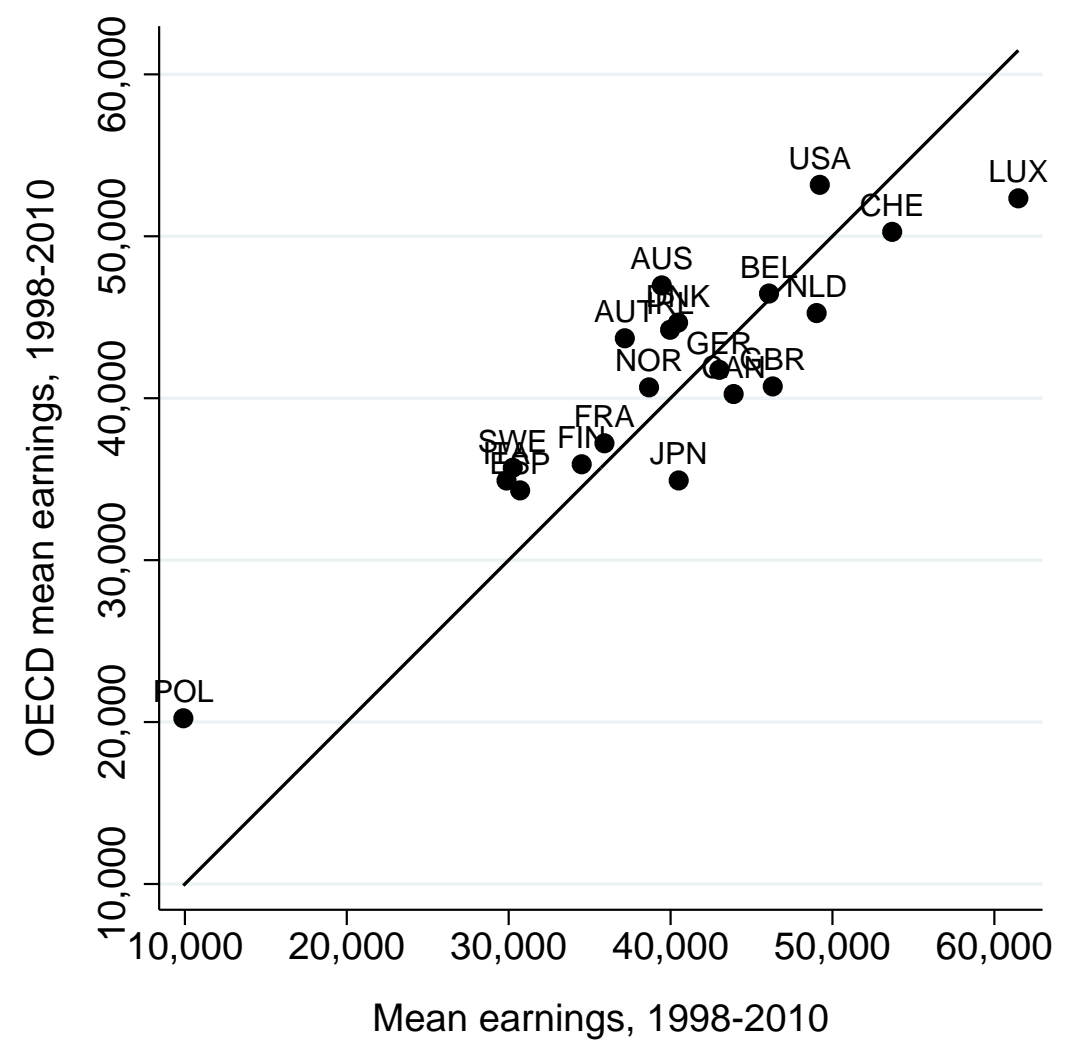

Notes: The figure plots our computed measure for average mean gross earnings between 1998 and 2010 against average earnings obtained from the OECD. The black line is a $45^{\circ}$ line. 
Table B.1: Adjusted earnings percentiles

\begin{tabular}{|c|c|c|c|c|c|}
\hline & & \multicolumn{2}{|c|}{ Uni graduates } & \multicolumn{2}{|c|}{ All } \\
\hline & & net & gross & net & gross \\
\hline \multirow[t]{4}{*}{ Australia } & Mean & 39,751 & 52,066 & 30,122 & 39,456 \\
\hline & P25 & 28,038 & 34,893 & 20,598 & 25,635 \\
\hline & $\mathrm{P} 50$ & 34,485 & 45,171 & 25,974 & 34,023 \\
\hline & P75 & 40,368 & 59,344 & 30,907 & 45,429 \\
\hline \multirow[t]{4}{*}{ Austria } & Mean & 35,804 & 54,016 & 25,236 & 54,016 \\
\hline & P25 & 25,117 & 35,005 & 17,476 & 35,005 \\
\hline & P50 & 32,197 & 48,124 & 22,789 & 48,124 \\
\hline & P75 & 41,195 & 65,211 & 29,879 & 65,211 \\
\hline \multirow[t]{4}{*}{ Belgium } & Mean & 31,891 & 55,952 & 26,264 & 46,081 \\
\hline & P25 & 22,755 & 35,411 & 19,874 & 30,929 \\
\hline & P50 & 27,567 & 48,366 & 23,745 & 41,662 \\
\hline & P75 & 34,966 & 69,947 & 29,145 & 58,307 \\
\hline \multirow[t]{4}{*}{ Canada } & Mean & 47,078 & 62,085 & 33,225 & 43,804 \\
\hline & P25 & 28,832 & 35,599 & 20,026 & 24,719 \\
\hline & P50 & 39,516 & 52,122 & 27,823 & 36,689 \\
\hline & P75 & 50,309 & 69,814 & 39,132 & 54,309 \\
\hline \multirow[t]{4}{*}{ Denmark } & Mean & 29,181 & 50,405 & 23,433 & 40,464 \\
\hline & P25 & 21,640 & 35,865 & 17,764 & 29,435 \\
\hline & P50 & 25,475 & 44,000 & 21,567 & 37,243 \\
\hline & P75 & 29,140 & 58,445 & 23,356 & 46,826 \\
\hline \multirow[t]{4}{*}{ Finland } & Mean & 32,061 & 47,343 & 22,561 & 33,300 \\
\hline & P25 & 23,966 & 32,415 & 17,394 & 23,509 \\
\hline & P50 & 28,461 & 42,025 & 19,895 & 29,369 \\
\hline & P75 & 33,477 & 55,351 & 23,207 & 38,354 \\
\hline \multirow[t]{4}{*}{ France } & Mean & 39,151 & 55,081 & 25,529 & 35,915 \\
\hline & P25 & 24,810 & 33,471 & 17,097 & 23,064 \\
\hline & P50 & 34,007 & 47,845 & 21,868 & 30,764 \\
\hline & P75 & 46,823 & 69,796 & 29,673 & 44,225 \\
\hline \multirow[t]{4}{*}{ Germany } & Mean & 34,791 & 59,957 & 24,947 & 43,010 \\
\hline & P25 & 25,160 & 39,269 & 18,322 & 28,606 \\
\hline & P50 & 30,932 & 53,316 & 22,482 & 38,771 \\
\hline & P75 & 38,368 & 72,562 & 27,069 & 51,212 \\
\hline
\end{tabular}


Table B.1 (continued)

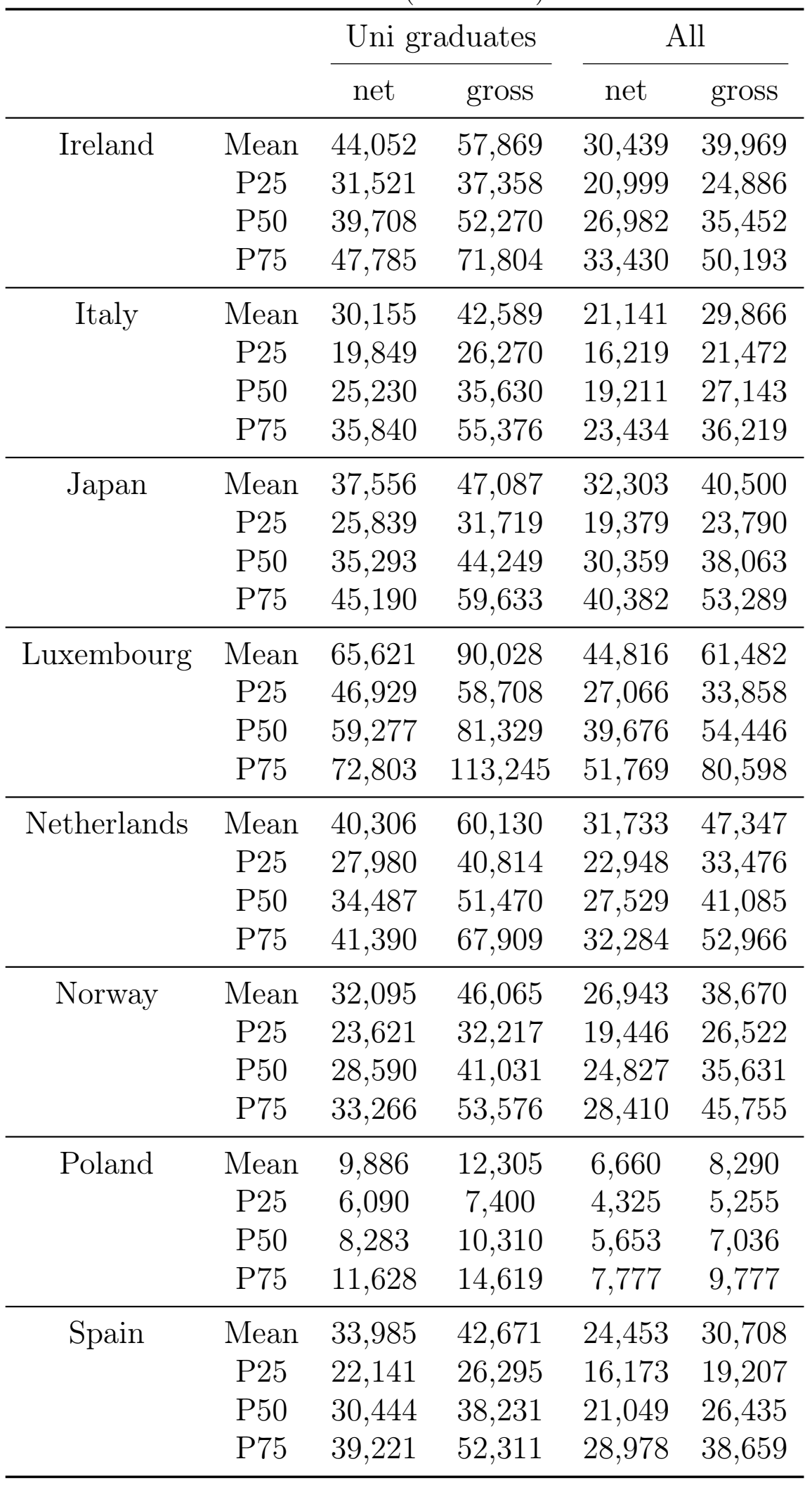


Table B.1 (continued)

\begin{tabular}{|c|c|c|c|c|c|}
\hline & & \multicolumn{2}{|c|}{ Uni graduates } & \multicolumn{2}{|c|}{ All } \\
\hline & & net & gross & net & gross \\
\hline \multirow[t]{4}{*}{ Sweden } & Mean & 24,690 & 36,377 & 20,540 & 30,251 \\
\hline & $\mathrm{P} 25$ & 17,143 & 24,519 & 14,747 & 21,086 \\
\hline & P50 & 21,627 & 31,851 & 18,819 & 27,710 \\
\hline & P75 & 25,100 & 42,143 & 21,002 & 35,254 \\
\hline \multirow[t]{4}{*}{ Switzerland } & Mean & 59,760 & 68,756 & 46,610 & 53,688 \\
\hline & $\mathrm{P} 25$ & 44,463 & 50,950 & 33,867 & 38,996 \\
\hline & P50 & 54,739 & 62,943 & 42,039 & 48,333 \\
\hline & P75 & 68,951 & 79,418 & 54,113 & 62,264 \\
\hline \multirow[t]{4}{*}{ UK } & Mean & 49,582 & 67,625 & 33,958 & 46,309 \\
\hline & P25 & 30,733 & 40,239 & 20,011 & 26,199 \\
\hline & P50 & 39,983 & 54,535 & 27,569 & 37,600 \\
\hline & P75 & 53,003 & 76,090 & 37,356 & 53,629 \\
\hline \multirow[t]{4}{*}{ United States } & Mean & 49,502 & 65,442 & 37,234 & 49,217 \\
\hline & $\mathrm{P} 25$ & 27,432 & 35,125 & 19,474 & 24,935 \\
\hline & P50 & 38,635 & 51,074 & 28,976 & 38,303 \\
\hline & P75 & 52,929 & 76,303 & 40,306 & 58,097 \\
\hline
\end{tabular}

Notes: The table shows adjusted earnings percentiles by country. The data are restricted to 1998-2010 and include inter- and extrapolation between the years. The measures are denoted in ppp-adjusted 2005 U.S. dollars. 
Table B.2: Country Data

\begin{tabular}{lccc}
\hline & $(1)$ & $(2)$ & $(3)$ \\
Country & Unemployment rate & Family expenditure & Life satisfaction \\
\hline Australia & 2.89 & 2.82 & 7.4 \\
Austria & 2.08 & 2.78 & 7.5 \\
Belgium & 3.42 & 2.66 & 7.1 \\
Canada & 4.65 & 1.08 & 7.6 \\
Denmark & 3.57 & 3.72 & 7.6 \\
Finland & 4.31 & 3.03 & 7.4 \\
France & 5.23 & 3.03 & 6.7 \\
Germany & 4.45 & 2.08 & 7.0 \\
Ireland & 2.90 & 2.85 & 6.8 \\
Italy & 5.43 & 1.35 & 6.0 \\
Japan & 3.29 & 0.79 & 6.0 \\
Luxembourg & 3.06 & 3.54 & 7.1 \\
Netherlands & 2.12 & 1.64 & 7.4 \\
Norway & 1.77 & 3.05 & 5.7 \\
Poland & 4.62 & 1.13 & 6.2 \\
Spain & 8.06 & 1.13 & 7.4 \\
Sweden & 3.78 & 3.34 & 7.8 \\
Switzerland & 2.27 & 1.22 & 6.9 \\
United Kingdom & 2.46 & 3.12 & 7.0 \\
United States & 2.89 & 0.75 & 5.7 \\
\hline
\end{tabular}

Notes: Unemployment rates are unemployment rates of 25-64 year-olds with tertiary education and family expenditure are public expenditures on family benefits as a percent of GDP. Both series are simple averages for the years 1998 to 2010. Life satisfaction is an average score and considers people's evaluation of their life as a whole. The reference year is 2013 for all countries with the exception of 2012 for Norway, Switzerland, and the United States and 2011 for Japan. Data come from the OECD. See section B.2 for details. 